\title{
Tres críticos franceses de Emilia Pardo Bazán $(1885-1886)^{*}$
}

\author{
Santiago Díaz Lage \\ (UNIVERSIDADE DE SANTIAGO DE COMPOSTELA) \\ santiago.diaz.lage@usc.es
}

(recibido novembro/2017, revisado xaneiro/2018)

RESUMEN: Se estudian aquí las valoraciones de la obra de Emilia Pardo Bazán que hicieron, entre 1885 y 1886, tres críticos franceses: Armand-Germain de Tréverret, Albert Savine y Boris de Tannenberg. Para mejor calibrar su calidad y su mérito, se comparan los juicios de cada uno de ellos con los que emitió la crítica española sobre las que eran entonces las novelas más recientes de la autora: La Tribuna y El cisne de Vilamorta. Este análisis permite conocer mejor las condiciones y las implicaciones de la recepción de la literatura española del momento en Francia.

PALABRAS CLAVE: Emilia Pardo Bazán (1851-1921): crítica e interpretación. La Tribuna: crítica e interpretación. El cisne de Vilamorta: crítica e interpretación. Armand-Germain de Tréverret (1836-1905), Albert Savine (1859-1927), Boris de Tannenberg (1864-1914): crítica e interpretación. Recepción de la literatura española en Francia. Transferencias, relaciones y mediaciones culturales: España y Francia, siglo XIX.

ABSTRACT: In this paper I analyze the readings of Emilia Pardo Bazán's literary works published in 1885-1886 by three French critics: Armand-Germain de Tréverret, Albert Savine and Boris de Tannenberg. In order to evaluate their quality, their judgements are compared with some contemporary Spanish reviews of the writer's most recent novels, La Tribuna and El cisne de Vilamorta. The comparison sheds some light on the conditions and the implications of the reception of Spanish literature in France.

KEY WORDS: Emilia Pardo Bazán (1851-1921): contemporary critical reception. La Tribuna: criticism and interpretation. El cisne de Vilamorta: criticism and interpretation. Armand-Fermain de Tréverret (1836-1905), Albert Savine (1859-1927), Boris de Tannenberg (1864-1914): criticism and interpretation. Critical reception of Spanish literature in France. Transfers, relations and cultural mediations: Spain and France, Nineteenth-Century.

\footnotetext{
* Este artículo deriva del trabajo realizado durante una estancia de investigación en el centro RIRRA21 de la Universidad Paul Valéry de Montpellier, sede en Francia del proyecto internacional Médias 19, gracias a una ayuda a la formación posdoctoral concedida por la Xunta de Galicia en el marco del Plan gallego I2C. Su autor es miembro del proyecto Ediciones y estudios críticos sobre la obra literaria de Emilia Pardo Bazán (FFI201680516-P), financiado por el Ministerio de Economía y Competitividad.
} 
Siguiendo el ejemplo de un estudio reciente de Jean-François Botrel (2008), se analizan aquí algunos "petits échos du grand réalisme espagnol dans la critique littéraire française». Aunque tenues y localizados, esos ecos son significativos por sí mismos y porque, a largo plazo, darán pie a establecer la filiación cultural del realismo español y su especificidad estética e ideológica en la historia de la novela europea. Con el ánimo de contribuir a esa tarea, y sin mayor voluntad de generalizar, me propongo comparar los juicios de tres críticos franceses que a mediados de la década de 1880, en los años del triunfo de la prosa y la novela (Blanco Asenjo 1885), se ocuparon del movimiento literario español y, más en particular, de la figura y la obra de Emilia Pardo Bazán: Armand-Germain de Tréverret (1836-1905), Albert Savine (1859-1927) y Boris de Tannenberg (1864-1914).

El nombre de Tréverret, parisino afincado en Burdeos, no les será desconocido a los lectores de Pardo Bazán, porque este «docto hispanófilo», profesor de la Facultad de Letras de Burdeos, fue uno de los promotores de su viaje a esta ciudad, en 1896, y posiblemente también de la invitación que la llevó a la Sociedad de Conferencias de París en 1899, como ella misma recuerda en el prólogo a La España de ayer y la de hoy (Pardo Bazán s. d. [1899]: 6-7; cfr. Tannenberg 1899). En su abundante producción crítica destaca la serie de artículos que publicó entre marzo y julio de 1885 en la revista parisina Le Correspondant bajo el título de "La littérature espagnole contemporaine: le roman et le Réalisme", no muy estudiada a pesar de su importancia para la historia de la recepción de la novela española en Francia. Poco antes había dado una conferencia sobre "Le Naturalisme espagnol" en la Société Filomatique de Burdeos, recogida en Le Courrier de la Gironde del 17 de marzo de 1885, y apenas dos años después, entre enero y julio de 1887, se insertaría en la Revue Britannique de París su traducción de Pedro Sánchez, de José María de Pereda (González Herrán 1983: 479 y 482; y cfr. García Castañeda 2017: 218-219). Por no desviarme de mi asunto, me ceñiré aquí a los comentarios sobre Pardo Bazán que encontramos en los artículos de Le Correspondant, pero confío en que por ellos se conocerá el valor y el mérito de los estudios de Tréverret.

Gracias a varios epistolarios, a las Memòries literàries de Narcís Oller (1962) y a las investigaciones de Christiane Leroy-Brunneau (1978) y Esteban Gutiérrez Díaz-Bernardo (2009), conocemos bien la biografía, las relaciones literarias y las actividades críticas y editoriales de Savine, en las que Pardo Bazán gozó durante algún tiempo de cierto protagonismo: en su opúsculo Le naturalisme en Espagne (1885) la caracteriza como «une des forces du naturalisme espagnol plus par ses tentatives comme critique que par ses tentatives comme romancier» (Savine 2009 [1885]: 148), y esa doble dualidad, crítica y novela, realidad y promesa, se verá confirmada tanto en su panorama del naturalismo español como en el prefacio a su versión francesa de La cuestión palpitante (Pardo Bazán 1886). Probando una vez más su compromiso con la difusión de la obra de nuestra autora en Francia, en 1887 Savine editará también la traducción de Bucólica preparada por Leopoldo García Ramón (Freire López 2005: 25).

En cuanto a Tannenberg, no me ocuparé de la semblanza de Pardo Bazán que publicó en 1899 en Le Journal des Débats Politiques et Littéraires (Tannenberg 1899) y recogió después en su libro L'Espagne littéraire (1903: 299-316), sino de dos textos sobre El cisne 
de Vilamorta aparecidos en 1886 en un efímero periódico francófono madrileño, L'Espagne Politique et Financière, de cuya sección literaria se encargó con regularidad (Díaz Lage 2017). Además de ilustrar un aspecto de la recepción de una obra no muy estudiada, estos textos nos permiten asistir a la formación de los juicios de Tannenberg sobre la novela española de su tiempo. A diferencia de los de Tréverret, que pueden consultarse en Gallica, y del librito de Savine, reeditado hace pocos años, los artículos de Tannenberg no son de fácil acceso; de ahí que se transcriban en apéndice para facilitar su consulta.

El tema es amplio y mi análisis no podrá ser exhaustivo. Cuando escriben Tréverret, Savine y Tannenberg ya era considerable el número de los hispanisants, y sin duda la investigación en archivos y hemerotecas nos brindará más datos sobre los círculos en que se movieron y sobre los focos de recepción de la literatura española en Francia ${ }^{1}$. Pero los tres se distinguen entre sus pares por haberse consagrado a las letras contemporáneas y por haber entrado en contacto, no sólo epistolar, con la sociedad literaria española del momento. El análisis de sus textos pone de manifiesto que su interés por la literatura española estuvo condicionado por un haz de factores religiosos, políticos, diplomáticos, culturales y comerciales, pero también por la concatenación, no siempre clara a primera vista, de las relaciones personales en que aquellos se encarnan.

\section{ARMAND-GERMAIN DE TRÉVERRET}

La historia de la revista Le Correspondant, fundada en 1843 por Edmond Wilson y Victor-Amédée Waille, y relanzada unos años más tarde con el apoyo del Conde de Montalembert, es larga y compleja: durante el Segundo Imperio fue uno de los órganos de expresión de los católicos regalistas franceses y, más en particular, de los círculos liberales aglutinados en torno a los Orléans; y mantuvo relativa influencia en la opinión católica francesa hasta su desaparición en 1933 (Robert 2011: 221, 225; Boutry 2011: 441).

En la década de 1880, Tréverret publicó en Le Correspondant varios artículos sobre la literatura y la cultura españolas de su tiempo (cfr. Tréverret 1885b y 1887). Los que aquí nos ocuparán empiezan acogiéndose al ejemplo de L. Louis-Lande, hispanófilo francés que había escrito varios ensayos sobre temas similares a mediados y finales de la década de 1870 (Tréverret 1885a: 1096; cfr. Romero Tobar 1992: 34-53 y 119-133). En aquel tiempo, señala Tréverret, la influencia del realismo francés en España era todavía bastante limitada, y dos novelistas se disputaban el favor del público, Juan Valera y Pedro Antonio de Alarcón; hacia 1885, en cambio, el público parecía atraído, como en los años inmediatos al Romanticismo, por las novedades editoriales venidas de Francia: «chez tous les libraires de Madrid, les romans des Goncourt, des Zola, des Daudet, se vendent fort bien, en français ou en traduction», y "le 23 juin 1883, on a fait bon accueil au drame de I'Assommoir, mis en espagnol sous le titre de La Taberna» (Tréverret 1885a: 1098). Pese al aparente éxito de público, el mundo literario se mantenía reluctante a la nueva tendencia, y tanto Antonio Cánovas del Castillo como Marcelino Menéndez Pelayo -son los dos nombres que menciona Tréverret- rechazaban el realismo en arte y literatura. «Au milieu de ce conflit

\footnotetext{
${ }^{1}$ Cfr. Álvarez Rubio (2007), especialmente pp. 261-319, y Charques Gámez (2016).
} 
et de l'incertitude qu'il jette dans I'esprit du public» (ibid.), sólo Armando Palacio Valdés y Emilia Pardo Bazán habían tomado partido públicamente por el realismo y se habían dedicado a escribir novelas basadas en sus principios.

El primer sesgo de los artículos de Tréverret es religioso y político: Palacio Valdés es «un homme peu ami du passé et à qui la religion semble avoir jusqu'à ce jour inspiré plus de doutes que de sympathies», mientras que Pardo Bazán es «catholique fervente et monarchiste déterminée» (Tréverret, 1885a: 1099). La misma dualidad elemental vincula, en el centro de su canon, los nombres de Benito Pérez Galdós y José María de Pereda, en quienes también se encarnan posiciones políticas diferentes, si no encontradas; parece claro, pues, que a pesar de la controversia suscitada por la nueva corriente, Tréverret se resistía a identificar la tendencia literaria con una única tendencia política; llegado a este punto, ya no se refiere a aquella como «realismo» o «naturalismo», sino directamente como «réalisme français», quizá porque consideraba la polémica naturalista más como aspecto de la recepción de la novela francesa en España que como elemento de una producción autóctona y reacción a ella.

A Pardo Bazán le dedica el crítico bordelés la primera sección de sus artículos. Empieza con una breve semblanza de la autora: pondera que escribe el francés «avec une pureté merveilleuse», y que «elle a étudié toute seule I'anglais et l'allemand, connaît les littératures étrangères, a beaucoup voyagé et s'est instruite de tout. Ni les mathématiques ni les sciences naturelles ne lui sont demeurées inconnues, et elle n'a pas plus craint d'écrire sur le darwinisme que sur les poètes épiques de l'Europe moderne» (Tréverret 1885a: 1100). Esta enumeración parafrasea la relación de títulos que por aquel entonces figuraba en las páginas iniciales de sus libros, sin mayores comentarios sobre las obras históricas, bastante bien conocidas, en algunos casos, por haberse publicado en revistas y periódicos de cierta circulación en Europa (como La Ciencia Cristiana). Sí se detiene Tréverret en La cuestión palpitante, «que M. Savine s'occupe à traduire», y en las tres primeras novelas largas de Pardo Bazán, especialmente La Tribuna.

En algunos pasajes de la semblanza parecen resonar declaraciones o confesiones de la propia autora. Al ver las amenazas de la revolución de 1868 contra «la société et la religion», escribe Tréverret, «elle se rejeta vivement en sens opposé, prêcha la croisade catholique et légitimiste, et ramena son père, qui était libéral, à des doctrines absolutistes et ultramontaines»; "l'impiété et le socialisme déchaînes par la révolution espagnole surtout en 1872 et 73, I'ont brouillée, peut-être à l'excès, avec des opinions qui sont encore bien loin de favoriser I'anarchie» (Tréverret 1885a: 1100). La idea de que la adhesión de Pardo Bazán a la causa carlista respondía a los supuestos desmanes de los revolucionarios y a la confusión del Sexenio no era nueva, y sin duda fue moneda corriente en la época; pero Tréverret pondera que sus ideas literarias nunca habían dejado de ser «libérales et même très avancées» $y$, al igual que el propio Zola, se sorprende de que una escritora tan fiel al dogma católico, y tan conservadora en lo político, fuese una de las principales promotoras del Naturalismo en España (ibid.: 1100).

Tréverret glosa varios textos de Pardo Bazán para calibrar su coherencia crítica y estética. Al hilo de la cuestión de lo verdadero, lo bello y lo bueno en el arte, se detiene 
en los pasajes de La cuestión palpitante donde se analiza la lucha de Gilliatt con el pulpo en Les travailleurs de la mer, de Victor Hugo, y en las escenas del conflicto religioso que aparecen en el capítulo XXIV de La Tribuna. Comenta a continuación algunas de las tesis de Pardo Bazán sobre el Naturalismo (que, a su parecer, la autora no distingue con mayor precisión del Realismo): por un lado, el idealismo conduce a la inverosimilitud y a la inexactitud, que disipan la ilusión de la ficción y mitigan su efecto en los lectores; por otro, el preciosismo verbal de escritores como Octave Feuillet o Juan Valera, sobre todo en los diálogos, puede falsear la correspondencia entre el texto y la vida. Aunque busca la verdad en literatura, Pardo Bazán rechaza la idea de Zola de que la novela naturalista «pourrait servir de document aux hommes politiques», y defiende que el arte no tiene por objetivo «l'enseignement, mais l'intérêt, le charme et l'émotion» (1885a: 1101). Pero ¿cómo puede conciliarse esa idea con el culto de lo bello, lo real y lo verdadero, y cómo define la autora estas categorías de la experiencia estética? Según Tréverret, tendía a asimilar lo que Ilamaba la realidad con la verdad y, al contraponer el realismo al idealismo, se abocaba a confundir el idealismo con la mentira: «il est vrai», concede, «que $M^{\text {me }}$ Pardo ne nie point le mérite des idéalistes et le plaisir que leurs œuvres font éprouver, mais elle croit que leur temps est passé, et que tout idéal porte en lui une part de faux dont on s'aperçoit toujours avec déplaisir» (1885a: 1103). Como muchos escritores realistas, Tréverret le otorgaba a la propia exposición de la verdad una función moral y didáctica, ya que «toute réalité, même sans qu'on le veuille, est un enseignement» (1885a: 1102); sin embargo, no se avenía a aceptar que el idealismo estaba periclitado porque, a su juicio, lo bello y lo verdadero, fundamentos morales del arte, trascendían la duración de lo real y se situaban en un plano superior de la existencia y la experiencia estética: en la medida en que suponía que la historia de la literatura, o de las artes en general, se regía por una lógica de superaciones progresivas, en que unas tendencias se imponen a otras, nutriéndose el apogeo de la decadencia, el oportunismo literario seguía suscitando polémica (Bonet 2002).

En el capítulo XVII de La cuestión palpitante, que se había publicado en la hoja literaria de La Época en marzo de 1883, Pardo Bazán censuraba las tendencias docentes y utilitarias de la novela británica, que «propende a enseñar y predicar, más bien que a realizar la belleza» (1989: 293), y se burlaba de la predicadora metodista que protagoniza Adam Bede, de George Eliot. Al hilo de esas observaciones, comenta Tréverret:

Si le protestantisme a eu tort d'enchaîner le roman à la morale, les catholiques ont peut-être commis l'imprudence de laisser le roman se tourner contre eux. Dans les pays où l'orthodoxie domine, presque tous les romans, même idéalistes, sont suspects aux prêtres, et il s'est créé là un antagonisme fâcheux auquel ont malheureusement contribué des hommes de toutes les opinions. (Tréverret 1885a: 1102).

La patente de corso de la ortodoxia se vuelve contra la autora, que la utilizó con frecuencia para justificar su intervención en los debates sobre el Naturalismo y sustanciar su postura en ellos. Pero la objeción de Tréverret se refería específicamente a los países donde la Iglesia tenía mayor poder político, cultural y social (cfr. Botrel 1982, e Hibss Lissorgues 1995): la estrategia de mantener un fuerte control sobre el impreso podía polarizar las 
opiniones, de modo que su eficacia quedaba restringida; a la larga, seguramente suscitaba en sus destinatarios más fascinación por el fruto prohibido que prudencia; y de rechazo, quienes debían ejercer aquel control de proximidad solían redoblar su celo, anticipándose no sólo a la beligerancia de los adversarios ya conocidos, sino también a las desviaciones de la curiosidad, las tentaciones del gusto y los vericuetos de la obediencia.

Las apreciaciones de Tréverret sobre las dos primeras novelas de Pardo Bazán no ofrecen mayor interés. De Pascual López sólo dice que era «une fantaisie, un conte d'alchimiste arrangé à la mode du jour, œuvre curieuse, colorée, pleine d'invraisemblances» (Tréverret 1885a: 1103). Se explaya más sobre Un viaje de novios: aunque algunos aspectos de la trama le parecen convencionales y novelescos, en el peor sentido de la palabra, alaba el talento de la autora para representar con viveza los ambientes y los caracteres, y reconoce que en la novela hay «plusieurs scènes que l'on n'oublie pas et qui sont bien empruntées à la vie réelle, pétrie de tristesse et de folie» (Tréverret 1885a: 1104). Resulta enigmática la alusión a "ces familles espagnoles, qui courent la France en quête d'amusements à la fois fébriles et fashionables»: su referente en la novela es claro, pero cabe preguntar si los lectores de estos artículos, franceses en su mayor parte, reconocerían en ellas a un tipo característico.

Teniendo en cuenta que desde su fundación Le Correspondant había mantenido posiciones próximas a las de la Compañía de Jesús y en algunas ocasiones había defendido a sus miembros, un detalle de la trama de Un viaje de novios no podía escapar a la atención de Tréverret. Los dos jesuitas que aparecen en la novela, el padre Urtazu y el padre Arrigoitia, son personajes positivos, y al final se confirma que la protagonista debería haber seguido sus consejos: "le prêtre catholique, aux yeux de $\mathrm{M}^{\mathrm{me}}$ Pardo, a le secret de la vie et la grâce des bons conseils; mais il peut être laid et drôle malgré la grâce, et de cette laideur, de cette drôlerie le réalisme s'empare en respectant le reste» (Tréverret 1885a: 1105). Fiel a los principios del realismo, y más aún a «la morale et le dogme catholiques», la autora enfatizaba el valor de aquellos consejos desmintiendo la realidad de las apariencias y mantener el respeto debido a la jerarquía eclesiástica. La elección de los apellidos de los dos jesuitas no ha de ser accidental, no sólo porque pudieran remitir a personas reales ${ }^{2}$, sino porque parecen adscribirlos a la rama vasca de la Compañía, muy afín a la causa carlista, sobre todo en zonas rurales. Por desgracia, nada dice nuestro crítico a ese respecto.

Más espacio le dedica a la que era entonces la última novela de Pardo Bazán, La Tribuna. El núcleo de su juicio es la cuestión del sesgo moral y la tendencia en el arte: la obra «semble avoir pour but de détourner le peuple des idées révolutionnaires», aunque la novelista, consecuente con sus postulados críticos, decía no haber sometido la invención a ningún propósito, limitándose a pintar «des faits que pendant deux ou trois ans j'ai eus sous les yeux; tant pis pour la révolution si ces faits lui donnent tort; moi, je ne les invente pas; je m'en souviens et je les raconte»(1885a: 1105). En esta paráfrasis -precipitada

\footnotetext{
${ }^{2}$ En la primera versión de los Apuntes autobiográficos la autora declara que «un [virtuoso y sabio] jesuita que viajó conmigo hasta Palencia, me sirvió de modelo, en cuanto al modo de hablar y pensar, para el P. Urtazu» (Freire López 2001: 335).
} 
pero expresiva - resuenan varios pasajes del prólogo a la novela, especialmente aquel donde explica la autora que el propósito «docente» que pudiera haber en ella «nació del espectáculo mismo de las cosas, y vino a mí, sin ser llamado, por su propio impulso»:

Porque no necesité agrupar sucesos, ni violentar sus consecuencias, ni desviarme de la realidad concreta y positiva para tropezar con pruebas de que es absurdo el que un pueblo cifre sus esperanzas de redención y ventura en formas de gobierno que desconoce, y a las cuales por lo mismo atribuye prodigiosas virtudes y maravillosos efectos. (Pardo Bazán 1999 [1883]: 58).

Era difícil que todos los elementos de la trama de La Tribuna coincidiesen en una misma historia real, y varios críticos han observado que el desenlace de la novela, en el mejor de los casos, resulta ambiguo (cfr., por ejemplo, Fuentes 1971, González Herrán 1988, y Sotelo Vázquez 2002: 30-31). Al resumir la obra, afirma Tréverret que las ilusiones amorosas mueven a Amparo a desvincularse poco a poco de la causa política que había defendido, y que tras su caída, desengañada ya, adopta posiciones cada vez más radicales. Añade entonces una apreciación más sutil:

Ce roman de mœurs populaires appelle une suite, et nous désirons qu'il en ait une. Soit que l'auteur nous réserve de plus fortes émotions, soit qu'elle continue à reproduire les agitations dont elle fut témoin, nous y trouverons sans doute ou une œuvre d'art intéressante ou ce que M. Zola nomme un document moral. (1885a: 1105).

Teniendo en cuenta que Amparo y sus compañeras acaban por enfrentarse a las consecuencias de algunos de sus actos, y que la historia de amor con Baltasar queda agotada en sus resultados, una hipotética continuación o segunda parte de la novela habría de plantear un conflicto diferente, en el que no resultaría fácil mantener la imbricación de lo biográfico y lo histórico que sostenía la primera. Tréverret, que conoce los referentes de la ficción, se pregunta cómo habría plasmado la novelista la decadencia y el fracaso de la República y, sobre todo, las posibles decepciones políticas de su protagonista, quizá porque considera el personaje de Amparo como encarnación simbólica de la idea que tenía Pardo Bazán sobre los orígenes, las causas y los resultados de la Revolución de septiembre. Desde ese punto de vista, el desenlace de la novela dejaba abiertos muchos interrogantes, como ya había señalado Jerónimo Vida en la reseña que le consagró en el Boletín de la Institución Libre de Enseñanza:

Concluye bruscamente la novela sin que el lector pueda averiguar ni figurarse lo que pasó después. ¿Siguió La Tribuna siendo federala? ¿Se hizo mujer de bien y se casó con Chinto? ¿Se vengó de su seductor? Problemas son estos que no puedo resolver con los datos que me suministra el conocimiento de los personajes. (Vida 1884: 77) ${ }^{3}$.

\footnotetext{
3 Quiero agradecerles a Laureano Bonet y a Teresa López Palma la eficiencia y la generosidad con que han compartido conmigo una copia de este artículo.
} 
Pero aquel final abría unas perspectivas que, como es sabido, Pardo Bazán desarrollaría más de diez años después. En su novela Memorias de un Solterón, que empieza a publicarse en La España Moderna en los primeros días de 1896, Sobrado reaparece como individuo libre, rico industrial y amante de una de las hijas de don Benicio Neira, Rosa: cuando sus relaciones están a punto de formalizarse, el narrador, Mauro Pareja, le recuerda a don Benicio que Baltasar siempre había sido «aficionado a las faldas, y a toda clase de faldas» (Pardo Bazán 2004: 169), y que no cabía esperar demasiado de su hombría de bien; se evoca entonces «la historia de la cigarrera», y en cuanto Neira empieza a disculpar el comportamiento de Sobrado, apelando a distintos principios del sentido común y a un tema de rica tradición literaria (González Herrán 2011), Pareja lo interrumpe:

-Aquello -insistí yo- fue muy mal hecho, D. Benicio. Se trataba de una real moza, una tal Amparo, a quien en la Fábrica conocían por la Tribuna, porque entonces, que eran republicanas la mayor parte de las cigarreras, esa pronunciaba discursos y leía periódicos y hasta tomó parte en un motín...

- Valiente sargentona!

-No, pero tenga usted entendido que era honrada; una niña, una pobre criatura... y este Baltasar, entonces oficial de infantería, la sedujo, parece que con palabra redonda de casamiento.

- ¡Palabra de casamiento, palabra de casamiento! ¿Y quién la mandó a la muy simple creer en cuentos de brujas? ¿Andan los oficiales por ahí casándose con las cigarreras? -protestó D. Benicio, impaciente-. ¡Casarse! Famoso punto será la tal -prosiguió cada vez más extraviado por su cariño de padre.

-iQué Neira de mi alma! -repliqué-. La muchacha era realmente intachable antes de que Baltasar la perdiese; y lo fue también después de ese desliz, porque hubo muchos galopos que quisieron recoger la herencia de Sobrado... y se encontraron con la horma de su zapato, se lo aseguro a usted. Ella siguió trabajando en la Fábrica, donde hoy es maestra; no se la conoció ni por casualidad otro devaneo, y además crió y mantuvo a las consecuencias de las humoradas del Baltasarito... que no ha sido nunca para echar mano a la cartera y enviar unos billetes de Banco a esa desdichada, a fin de que su hijo pudiese alimentarse mejor y educarse con algún decoro. Amparo ha sufrido crujías terribles de miseria, allá en los primeros tiempos, y pobre continúa, y su hijo más pobre aún, porque vive de su oficio de tipógrafo. (Pardo Bazán 2004: 169-170).

Es cierto que este resumen podría suscribirlo casi cualquier lector de La Tribuna, y que la defensa del comportamiento de Amparo se ajusta a la moral imperante en la época; pero conviene notar que los elementos en que incide Pareja son los mismos, y casi en el mismo orden, que había destacado Tréverret en sus artículos para caracterizar la evolución de la protagonista, irreprochable a lo largo de toda la novela:

Le caractère d'Amparo a de la noblesse. Dans sa faute même, elle conserve une grande dignité, n'ayant pas cédé qu'à une promesse formelle, et n'acceptant pas, comme plusieurs de ses compagnes, les cadeaux et l'argent d'un amant qui l'entretienne. Dès que son séducteur lui a tourné le dos, elle ne songe plus qu'à le punir et surtout à frapper la famille du jeune homme, qui s'est opposé au mariage. (Tréverret 1885a: 1106). 
No escapa a la atención del crítico que Amparo sólo cae en la tentación cuando Baltasar le promete, en el capítulo XXXI, que se casará con ella; pero atenúa los dilemas que le ofrece su deseo de desquitarse, y quizá exagera el peso de la familia Sobrado en la ruptura. Si unas líneas antes había vinculado la radicalización política de Amparo con su decepción, ahora queda claro que la sed de venganza individual, en la esfera íntima, le parece a Tréverret un sentimiento más comprensible. En Memorias de un solterón, la recapitulación de Pareja los conduce a Neira y a él a recordar a otro personaje humillado y ofendido por Baltasar: su hijo, el compañero Sobrado.

Si bien es difícil postular una relación directa entre los artículos de Tréverret y la novela Memorias de un solterón, las coincidencias textuales señaladas sugieren que Pardo Bazán pudo conocer los artículos de Le Correspondant. El primero de ellos se publicó en la entrega del 25 de marzo de 1885, y por distintas fuentes sabemos que ella estaba en París a finales del invierno y principios de la primavera de aquel año; pero no hay indicios positivos de que llegaran a sus manos, y cabe suponer que, de haberlos leído entonces, se lo habría comentado a alguno de sus corresponsales ${ }^{4}$. Seguramente los conoció más tarde: teniendo en cuenta que en 1894 estaba en contacto con la revista, donde Norbert Lallié había traducido y glosado sus artículos sobre "La mujer española" (Thion Soriano-Mollá 2003: 117), y que en 1896, apenas publicada Memorias de un solterón, viaja a Burdeos por invitación de Tréverret, la hipótesis de un diálogo textual entre la novelista y el crítico, o de una relectura de la propia obra a la luz de la interpretación ajena, cobra mayores visos de verosimilitud.

Pero a Tréverret se le escapa un detalle significativo: tras caer en la tentación, Amparo, que siempre había rechazado el dinero y los regalos de sus pretendientes, se endeuda para comprar prendas y joyas que pudiesen pasar por obsequios de su amante, para presentarlo implícitamente como su novio:

Ahora, durante sus relaciones con Baltasar, trabajaba más que nunca y se vestía lo mejor posible, para hacer creer que el señorito de Sobrado era con ella dadivoso. Se regocijaba interiormente de que la sostuviesen sus ágiles dedos, mientras el barrio le envidiaba larguezas que no recibía; es más, que rechazaría con desdén si se las ofrecieran. Su vanidad era doble: quería que el público tuviese a Baltasar por liberal, y que Baltasar no la tuviese a ella por mercenaria. (Pardo Bazán 1999: 227).

Como han destacado Geraldine Scanlon (1990) y Ana Mateos (2015), en la ficción el deseo de Baltasar se representa a Amparo como un objeto de consumo, si no una mercancía: la metáfora recurrente del cigarro, en que se encarnan las distintas formas de opresión que condicionan las relaciones de los amantes, expresa claramente el alcance erótico de sus relaciones, supeditándolo a su duración. En su estudio, Tréverret intentaba calibrar el extremo de veracidad explícita que alcanzaba la novelista al representar los aspectos más escabrosos de la realidad contemporánea, pero no le reprochaba la audacia

\footnotetext{
4 Por la fecha de una carta a Pereda (González Herrán 2016 [1983]: 169-171) sabemos que todavía estaba en París el 10 de marzo; sin embargo, no se conocen cartas enviadas desde París posteriores a la publicación del primer artículo de Tréverret.
} 
de sus planteamientos ni el rigor del método experimental que aplicaba, como ella querría, sino más bien su timidez y sus escrúpulos:

Dans ce roman, le vice bas et vénal n'est point oublié par l'auteur; elle le mentionne, mais le laisse au troisième plan; et à ceux qui s'en étonneraient ou la trouveraient trop timide, trop scrupuleuse, elle allègue une raison peu flatteuse, hélas, pour la France: «si j'avais à peindre, écrit-elle, le même peuple que Zola ou les Goncourt, je tracerais comme eux de hideux tableaux; mais, grâce au ciel, notre peuple espagnol n'en est point arrivé là; les nobles sentiments vivent dans son cœur, et ce serait contredire la réalité que de le peindre abruti et sans croyances».

Curieuse manière de concilier ensemble son admiration pour les chefs de l'école française et son dégout des longues ignominies qu'ils se sont complu à étaler! Elle aime mieux croire ignoble tout le peuple de Paris que de démentir ou de condamner la Fille Elisa et l'Assommoir. (Tréverret 1885a: 1106).

No se engaña Tréverret al atribuirle a nuestra autora una cierta fascinación por las representaciones artísticas del Naturalismo francés. Tomando sus imágenes del pueblo por referencia para estudiar la realidad española, resultaría evidente para Pardo Bazán que el verismo de ella, por el propio carácter de su objeto, no podría alcanzar nunca la indecencia ni la sordidez de las novelas naturalistas francesas. En dos textos cuyas concomitancias ya ha destacado la crítica (González Herrán 1989: 52-53), el prólogo a La Tribuna, fechado en Meirás en octubre de 1882, y el último artículo de La cuestión palpitante, aparecido en La Época a mediados de abril de 1883, escribe Pardo Bazán unas palabras que podrían dar la clave de las apreciaciones de Tréverret. En el prólogo a La Tribuna advierte:

Tal vez no falte quien me acuse de haber pintado al pueblo con crudeza naturalista. Responderé que si nuestro pueblo fuese igual al que describen Goncourt y Zola, yo podría meditar profundamente en la conveniencia o inconveniencia de retratarlo; pero resuelta a ello, nunca seguiría la escuela idealista de Trueba y de la insigne Fernán, que riñe con mis principios artísticos. Lícito es callar, pero no fingir. Afortunadamente, el pueblo que copiamos los que vivimos del lado de acá del Pirineo no se parece todavía, en buen hora lo digamos, al del lado de allá. Sin dar en optimista, puedo afirmar que la parte de pueblo que vi de cerca cuando tracé estos estudios me sorprendió gratamente con las cualidades y virtudes que, a manera de agrestes renuevos de inculta planta, brotaban de él ante mis ojos. El método de análisis implacable que nos impone el arte moderno me ayudó a comprobar el calor de corazón, la generosidad viva, la caridad inagotable y fácil, la religiosidad sincera, el recto sentir que abunda en nuestro pueblo, mezclado con mil flaquezas, miserias y preocupaciones que a primera vista lo oscurecen. Ojalá pudiese yo, sin caer en falso idealismo, patentizar esta belleza recóndita. (Pardo Bazán 1999: 59).

Según Tréverret, en la representación del pueblo relaja la autora el rigor de su procedimiento experimental: «le roman ouvrier de $M^{\text {me }}$ Pardo répond aux promeses de la préface; il montre le peuple espagnol facile à irriter, mais, dans sa colère même, jaloux de ne pas rompre avec le ciel» (1885a: 1106). Como cabía esperar, el ejemplo evocado es el de los altarcitos que había en los distintos talleres, en los que ve la autora la prueba de que «a medida que la revolución se desencadenaba y el republicanismo de la fábrica crecía, tomaban incremento las prácticas religiosas» (Pardo Bazán 1999: 180): si ya en 
su artículo "La cigarrera", anterior en algunos años a la redacción de la novela, había alabado la devoción y el desprendimiento de las cigarreras coruñesas (en Díaz Lage 2006: 378 y 379), al incorporar esta observación al relato se cuida de precisar que su progresiva radicalización política no había mitigado en absoluto sus sentimientos religiosos. "Dos cosas, sobre todo, alteraban la bilis de las cigarreras», dice la narradora en el capítulo XXIV: «el incremento del partido carlista y los ataques a la Virgen y a los santos». Glosando quizá esta afirmación, que precede a la descripción de los altares, Tréverret se deja llevar por el recuerdo de algunos episodios sueltos de la novela:

Or, un jour, où l'on annonçait que les carlistes, appelés et secondés par les prêtres, allaient peut-être conquérir l'Espagne entière, toutes ces plébéiennes, persuadées que la république seule aimerait et sauverait le peuple, s'écrièrent: «Mort à don Carlos, et mort aux curés qui le soutiennent!» Mais quand l'une d'elles, infectée par de mauvaises lectures et admirant la Commune de Paris, proposa de crier: "À bas la Vierge!» et de renverser le petit autel, I'indignation la plus vive éclata, et l'ouvrière impie, battue par ses compagnes, fut chassée ignominieusement. Le soir de ce jour-là, la statue brilla plus que jamais, entourée de cierges et de fleurs. (Tréverret 1885a: 1106).

En este párrafo hay varias imprecisiones. Según se indica en el capítulo XXIV de la novela, en la Granera «habría media docena de espíritus fuertes, capaces de blasfemar y de hablar sin recato de cosas religiosas»; pero «a lo sumo se permitían maldecir de los curas, acusarlos de inmorales y codiciosos, o renegar de que se "metiesen en política" y tomasen las armas para traer el "escurantismo y la Inquisición"» (Pardo Bazán 1999 [1883]: 181). Hasta donde sé, en ningún pasaje se profieren gritos contra la Virgen, aunque en una conversación entre cigarreras, también en el capítulo XXIV, se glosan las palabras de un diputado a Cortes por Cataluña que «dice que dijo que ya no había Dios y que la Virgen era esto y lo otro...»; las presentes se indignan, en efecto, pero no hay tumulto ni quimera. La alusión a la Comuna de París -única en la novela, si no me engaño- no se encuentra en aquel capítulo, sino en el XXXIV, en una escena que incluye amenazas contra el clero y contra los ricos, pero no contra don Carlos. Salvo error por mi parte, la obrera que se granjea la hostilidad de sus compañeras es la Píntiga, no por sus impiedades y blasfemias, sino porque se rumorea que se ha vendido a los «inglis manglis» y se ha convertido al protestantismo (también en el encuentro con los delegados de la Sociedad Bíblica durante la fiesta de "las Comiditas», en el capítulo XXV, se produce una pequeña escaramuza). Seguramente Tréverret escribía de memoria y, queriendo justificar con ejemplos su lectura de la novela, confundió varios episodios diferentes en una única anécdota; también entra en lo posible que estas imprecisiones se debiesen a una lectura precipitada o a una comprensión defectuosa de algunos diálogos, en los que el lenguaje intencionado de los personajes podría ser difícil para un lector extranjero ${ }^{5}$.

\footnotetext{
5 A propósito del párrafo que acabo de citar, escribe Tréverret: «toute cette scène est curieuse et contée avec verve; les libres penseurs ont pu se plaindre de voir l'Espagne si arriérée, mais tous ont reconnu le talent de $\mathrm{M}^{\mathrm{me}}$. Pardo, et n'ont pu récuser le chaleureux témoignage qu'elle rend ici à la foi du peuple espagnol» (1885 a: 1106). No resulta fácil saber con seguridad a quiénes se refería, aunque tanto Clarín como Jerónimo Vida reseñaron $\mathrm{La}$ Tribuna y ninguno criticó el tratamiento de las clases populares en ella.
} 
Llama la atención que Tréverret no profundice más en la cuestión religiosa: Ilevado quizá por su visión de la sociedad española, o por un conocimiento parcial de la historia del Sexenio, la presenta ante todo como una tensión entre la religiosidad (la fidelidad heredada al catolicismo) y la impiedad (las tendencias secularizadoras del liberalismo revolucionario); pero en La Tribuna también se plasma la confrontación entre el catolicismo hegemónico y las iniciativas evangelizadoras de los protestantes británicos que se instalaron en Coruña y en otras zonas de Galicia al proclamarse la libertad de religión y de conciencia en 1869. La hostilidad de Amparo y de sus compañeras hacia los colporteurs evangélicos es sintomática, no sólo porque capta un fenómeno característico de los años en que se sitúa la acción de la novela, sino también porque en Coruña la influencia del protestantismo sería especialmente intensa, andando el tiempo, en las mujeres de clase obrera y menestral (González Raposo 1999: 33-48). Cuando se publica La Tribuna, en 1883, las comunidades protestantes estaban ya arraigadas en la ciudad y, aunque las conversiones eran poco frecuentes, habían trascendido el ámbito de la colonia británica.

En el prólogo a La Tribuna, la autora se ceñía a la contraposición elemental que luego pondrá de relieve Tréverret, según la cual el pueblo español no era (todavía) como el pueblo francés. Pero en los artículos de Le Correspondant resuena también, como antes avancé, uno de los últimos párrafos de La cuestión palpitante, donde la cuestión reviste formas más complejas:

No estamos muy lucidos, en cierto respecto, los iberos; mas los pensadores de la nación vecina hablan de una cosa terrible que Ilaman finis Galliae y explica las sombrías tintas del naturalismo francés. Acá, los que estudiamos el pueblo, no ya en las aldeas, no en las comarcas montañosas, que gozan fama de morigeradas costumbres, sino en un centro obrero y fabril, notamos -sin pecar de optimistas- que, a Dios gracias, nuestras últimas capas sociales se diferencian bastante de las que pintan los Goncourt y Zola. Así el realismo, que es un instrumento de comprobación exacta, da en cada país la medida del estado moral, bien como el esfigmógrafo registra la pulsación normal de un sano y el tumultuoso latir del pulso de un febricitante. (Pardo Bazán 1989: 326-327) .

La distinción entre el pueblo de «las aldeas» y «las comarcas montañosas» y el de «un centro obrero y fabril» encierra un doble sobrepujamiento: rigurosa en su búsqueda de la Verdad, como materia narrativa que puede encontrarse, la novelista no ha ido a estudiar al pueblo allí donde se conservan costumbres morigeradas, sino al lugar donde estas podrían verse amenazadas por las dinámicas sociales contradictorias que animaban la trama de su novela. La contraposición entre las costumbres del pueblo rural y las del pueblo urbano y fabril ya tenía algo de entimema ideológico cuando se le aplicaba a una novela, La Tribuna, que no ignoraba las circunstancias del éxodo rural, las dificultades del asentamiento en las ciudades ni las tensiones que acompañaron a la urbanización urgente e incompleta de la periferia suburbana; cuando en obras posteriores la observación de la autora se centre en otras regiones, quedará claro que la fama de las buenas costumbres rurales, sin

\footnotetext{
${ }^{6}$ Este párrafo no aparece en la traducción de La cuestión palpitante que hizo Albert Savine, muy libre en algunas partes de los capítulos sobre la novela española (cfr. Pardo Bazán 1886: 305-316).
} 
duda convencional, tampoco resistía el análisis naturalista. Pero es interesante recordar que Tréverret también seguía un principio de interpretación geográfica al contraponer la periferia provincial donde escribía la autora a la capital donde «los librepensadores» y la prensa utilizaban la literatura como instrumento de las contiendas políticas.

La sección dedicada a Pardo Bazán termina comparando los capítulos IV y V de La Tribuna con la «nouvelle andalouse» "La noche de Navidad" de Fernán Caballero, «traduite jadis en français par Germond de Lavigne» (Tréverret 1885a: 1107) ${ }^{7}$. La comparación pone de relieve la distancia que separa a la escritora idealista de la ferviente realista que era, o declaraba ser, Pardo Bazán: en el cuento de aquella «tout nous est montré agréable et touchant», $y$ «toute trace des fautes et des misères humaines est effacée par la sainte croyance au Christ», mientras que la autora de La Tribuna no elude ningún aspecto que pueda poner de manifiesto los contrastes: «fêtes et souffrances, élégances et dénuement s'offrent à elle et se retrouvent sous son pinceau». La comparación cierra con eficacia el capítulo: Fernán Caballero era un referente en el oficio de escribir y en las concepciones del arte literario que Pardo Bazán quería contribuir a superar, como ya demostraban un artículo temprano publicado en El Heraldo Gallego en 1878 y algunos pasajes de La cuestión palpitante (Clemessy 1973: 49; González Herrán 1989: 46-47).

\section{ALBERT SAVINE}

También en 1885 se publicó en París el célebre opúsculo de Albert Savine, Le naturalisme en Espagne. Su autor no era desconocido en la sociedad literaria ibérica: desde principios de la década había colaborado con regularidad en distintas publicaciones próximas al espíritu del felibre y de la Ilamada idea latina -como la Revue du Monde Latin de París, fundada en 1883 por el barón Charles de Tourtoulon, en la que también escribía Boris de Tannenberg- y había traducido L'Atlántida, de Jacint Verdaguer, El comendador Mendoza, de Juan Valera, y al menos uno de los Croquis del natural de Narcís Oller. Como es sabido, poco tiempo después también sería autor y principal promotor de la versión francesa de La cuestión palpitante, publicada en 1886 por la Nouvelle Librairie Parisienne de Giraud, con algunos juicios de Émile Zola y un prólogo del mismo Savine que Pardo Bazán reproduciría, con tres notas aclaratorias, en la «cuarta edición» de su obra (González Herrán 1989: 59-61). Ya a principios de 1885 se había insertado en La Revue du Monde Latin, a modo de adelanto, una refundición en francés de los capítulos noveno y décimo, en los que Pardo Bazán analizaba la estética y la obra de Stendhal, Honoré de Balzac y Gustave Flaubert (Pardo Bazán 1885a): en la medida en que le presentaban al público francés a una fina lectora extranjera de su novela reciente, eludiendo las polémicas asociadas al naturalismo, aquellos capítulos podían ser los más adecuados para dar a conocer la obra.

\footnotetext{
7 Alfred Germond de Lavigne (1812-1891) tradujo al francés La Celestina y el Buscón, así como algunas novelas de Benito Pérez Galdós (López Jiménez 1990). Si no me equivoco, su versión de "La noche de Navidad" se publicó por primera vez en el libro Nouvelles andalouses: scènes de mœurs contemporaines par Fernán Caballero, traduites de l'espagnol avec l'autorisation de l'auteur par A. Germond de Lavigne, Paris, Librairie de Louis Hachette et Cie., 1859, pp. 73-102. Sobre su actividad y sus traducciones véase Cabo Aseguinolaza (2012: 193-196).
} 
Por distintas fuentes sabemos que Savine y Pardo Bazán se conocieron en París a principios de 1885 (Oller 1962: 75-101; González Herrán 2016 [1983]: 169-171, 171 173). Parece que la simpatía fue inmediata, y ya en una carta a Oller del 12 de enero alaba ella que Savine es "persona muy agradable y razonable» y «conoce muy bien nuestra literatura», aunque se sorprende de que viviendo en París no esté en contacto con Zola ni con Daudet (Mayoral 1989: 404-405). No será esta la única ocasión en que se descubra una cierta divergencia entre las realidades de la sociedad literaria parisina y la imagen que de ellas se había formado nuestra autora: no parece que en la experiencia de los hispanisants de su tiempo se diesen las correspondencias que ella consideraba naturales entre los círculos de sociabilidad y los ambientes literarios, y acaso el interés de Savine por el naturalismo todavía no se había impuesto por completo a su entusiasmo panrománico y felibrista. Sea como fuere, los gestos de la novelista coruñesa y el crítico languedociano son complementarios, si no simétricos: si la una tiende a buscar lo que considera el centro de la tendencia estética y el sistema cultural en que se inscribe voluntariamente, el otro sólo Ilega a dicho centro a través de su interés por unas culturas, la catalana y la española, que ocupaban un lugar periférico dentro de Europa.

En Le Naturalisme en Espagne, Savine se propone demostrar que «l'esprit de race» «avait préparé en Espagne un terrain merveilleusement prédisposé à la floraison du naturalisme» (Savine 2009: 124). Por supuesto, no era el primero en señalar que el Naturalismo se compadecía bien con «nuestro realismo nacional, tradición gloriosísima del arte hispano» (Pardo Bazán 1999 [1881]: 197), aunque algunos de los postulados estéticos y políticos de la nueva tendencia eran difícilmente aceptables para la moral dominante, si no contrarios a ella. Savine asociaba aquella afinidad con un rasgo cultural y étnico que disolvía la aparente novedad en la larga duración de una tradición ignorada, o velada por la historia literaria reciente; el espíritu de la raza era, a su juicio, «l'esprit wisigoth», «toujours tourné vers le côté pratique des choses, en dépit des rodomontades et des redondances de langage des Ibères méridionaux, en dépit des influences orientales, qui ont mis tant de bleu vague et de rêves dans les imaginations andalouses»(ibid.). La idea de que el espíritu español tenía su origen en la época visigoda y en la conversión de Recaredo era un motivo central de la historiografía de inspiración nacional-católica desde mediados del siglo (Álvarez Junco 2001: 417-431), y Savine agrega la literatura a aquella amalgama de la Nación, la identidad colectiva y la religión.

Según Savine, en el siglo XVIII la influencia del clasicismo francés había asfixiado el espíritu nacional español, en el que convivían, al menos desde el Siglo de Oro, la forma realista y la forma idealista que él identificaba con Miguel de Cervantes y con Pedro Calderón de la Barca. Es interesante comprobar que aquella dualidad, crucial en la crítica de la novela contemporánea, constituía para Savine un fundamento del «espíritu nacional» pronto amenazado por el prestigio de las letras francesas; sólo con «la grande farandole romantique» guiada por el Duque de Rivas unos cuantos escritores se deciden a pintar las costumbres locales contemporáneas siguiendo, paradójicamente, los modelos de Paul-Louis Courier de Méré y Victor-Étienne-Joseph de Jouy; entre ellos destaca Savine los nombres de Serafín Estébanez Calderón, Ramón de Mesonero Romanos, Mariano José de Larra y 
Antonio Flores. Los dos primeros reaparecen como precursores del realismo español, junto a Fernán Caballero, antes del «resurgir de la novela idealista» que Savine identifica con los éxitos controvertidos de Pedro Antonio de Alarcón y de Juan Valera: tras ellos, concluye, «le roman idéaliste agonise en Espagne, non pas faute de lecteurs, mais faute de romanciers» (Savine 2009: 128). Retirados Valera y Alarcón, al menos en apariencia, los pocos escritores que seguían cultivando la novela pertenecían al campo realista:

Ceux-ci (M. Pérez Galdós) sont aujourd'hui des convertis qui combattent à la tête de la nouvelle école; ceux-là ( $M$. de Pereda), des indépendants qui en ont été les pionniers et qui seulement se refusent à accepter toutes les conséquences des nouveaux canons. (Savine 2009: 128).

Como ha recordado Esteban Gutiérrez Díaz-Bernardo (en Savine 2009: 206-207, n. 61), estas afirmaciones despertaron ciertas reservas en Clarín, quien no descartaba que Valera y Alarcón volviesen a publicar novelas que serían, como suyas, obras de mérito y dignas de interés. La propia Pardo Bazán reconocía, en varios lugares que recoge el citado crítico, que la oposición de la escuela idealista y la escuela realista, tan importante en los artículos de La cuestión palpitante, no bastaba a explicar por completo la realidad literaria de su tiempo. Pero, los juicios de Savine no apuntaban sólo a una cuestión crítica, sino a la lenta evolución de los gustos literarios y a las complejas relaciones de los escritores con sus lectores contemporáneos: quizá el público esperaba y buscaba aún obras de las viejas tendencias, mientras los novelistas más notables empezaban a explorar posibilidades y direcciones apenas apuntadas por sus homólogos franceses. De entrada, la opinión de Savine parece contradecir las de Tréverret, que destacaba que las novelas realistas y naturalistas francesas habían conquistado el favor del público madrileño, aunque no el de la crítica; pero conviene recordar que, como ya hemos visto, no quedaba claro si aquel juicio se aplicaba por igual a las novelas importadas de Francia (traducidas o no) y a las producciones autóctonas.

En el centro del canon contemporáneo de Savine se encuentran Pereda y Pérez Galdós, pero sus apreciaciones sobre Pardo Bazán, Palacio Valdés y Narcís Oller revelan un conocimiento directo del estado de las letras en España. Completan el panorama algunos apuntes sobre los dos primeros ensayos narrativos de Jacinto Octavio Picón, Lázaro y La hijastra del amor, y sobre la obra, narrativa y crítica, de José Ortega Munilla, así como algunas consideraciones sobre los campos enfrentados en la polémica naturalista y sus figuras más conspicuas. Fuera ya de la esfera del arte, más allá de los márgenes y de la periferia, está Eduardo López Bago, que «n'est pas un naturaliste», sino «un pornographe sans talent, sans dignité artistique» (Savine 2009: 156).

Savine presenta a Pardo Bazán como escritora bregada en géneros y asuntos serios: «philosophie, théories darwinistes, critique religieuse et littéraire, elle avait exercé sa plume dans tous ces genres graves: elle avait mis au jour un roman, réaliste à la manière des picaresques, assez bien construit d'ailleurs, quoique enfantin de thème: Pascual López» (Savine 2009: 138). A diferencia de Tréverret, también menciona el ensayo sobre San Francisco de Asís (Siglo XIII), del que sólo dice que está «écrit dans un esprit très 
modéré», acaso para conciliar las aparentes paradojas del carácter y la trayectoria de la autora, que en poco tiempo había pasado sin solución de continuidad de aquellos estudios a la novela de vocación realista con Un viaje de novios (Savine 2009: 150). Para Savine, la obra crítica de Pardo Bazán, y especialmente La cuestión palpitante, era el lugar donde habían de dirimirse aquellas antinomias entre la doctrina de la publicista y la práctica de la novelista: aunque una de las claves de esa conciliación es la reivindicación de «nuestro realismo nacional, tradición gloriosísima del arte hispano», el crítico francés subraya que fue la lectura de los hermanos Goncourt, «pour qui elle se prit d'une vraie passion», lo que inclinó hacia la novela y el realismo a aquella escritora que «appartenait par ses publications antérieures, ou plutôt semblait appartenir à l'école néo-catholique» (Savine 2009: 150).

La conciencia literaria de Pardo Bazán está marcada por la tensión entre una clave nacionalista y una clave esteticista, tensión que posiblemente explique los límites de su adhesión a los postulados del Naturalismo doctrinario. Savine y Tannenberg reconocen sin dificultades los modelos de la novelista, pero no valoran su incidencia textual igual que solían hacerlo los críticos españoles más avanzados; luego veremos que el examen de la literatura francesa contemporánea era un momento fundamental en la negociación de la especificidad estética de la novela moderna: la comparación con los Goncourt, por ejemplo, ya la había apuntado Clarín en su reseña de La Tribuna, publicada en El Día el 2 de marzo de 1884 y recogida dos años después en ...Sermón perdido:

Si algún día prospera tanto el género en España, que se pueda decir: este es el Balzac español, este es el Flaubert, este es el Daudet, etcétera, a la señora Pardo le convendrá la comparación con Goncourt. De todos los novelistas del naturalismo, son los Goncourt los que más pintan y los que más enamorados están del color. La señora Pardo es de todos los novelistas de España el que más pinta: en sus novelas se ve que está enamorada del color y que sabe echar sobre el lienzo haces de claridad como Claudio Lorena. (Alas 2003: 542).

En sentido estricto, el juicio de Savine, quizá fundado en una confidencia de la autora, no se refiere a la incidencia de un influjo estético en los textos de la escritora, sino a una predilección de la lectora; pero viene a reforzar una impresión que con el tiempo llegará a ser un lugar común crítico (cfr., sobre un período posterior, González Arias 1989, o 1992: 150-165). Como hemos visto, Tréverret no se había detenido a analizar la posible influencia de la novela francesa contemporánea en las obras de Pardo Bazán, ni llegó a singularizarla en ningún autor u obra concreta.

Savine, buen conocedor de sus textos críticos, presenta a la novelista Pardo Bazán como una promesa, y no como una realidad confirmada. Pero augura que «dans les deux volumes que prépare en ce moment $\mathrm{M}^{\mathrm{me}}$. Pardo» habrá «sans doute» otros "petits chefs d'œuvre» como la novela corta Bucólica, aparecida en la Revista de España en 1884, cuya traducción francesa, firmada por Leopoldo García Ramón, editará el propio Savine en 1887. En una escueta nota al pie añade que «Le Cygne de Vilamorta qui vient de paraître est de beaucoup supérieur aux oeuvres antérieures de $M^{\text {me }}$ Pardo» (2009: 150, n. 
1). Lo reciente de la publicación no permite ahondar en el juicio, pero tampoco le resta seguridad.

\section{BORIS DE TANNENBERG}

De El cisne de Vilamorta se ocupó Tannenberg en la causerie littéraire que publicó el 10 de junio de 1886 en L'Espagne Politique et Financière, y en una nota que aparece, sin firma, en la sección bibliográfica del mismo número (Díaz Lage 2017). Las palabras que abren la causerie marcan un giro respecto de otras semblanzas de la autora: «Mme Emilia Pardo Bazán», escribe Tannenberg, «appartient à la pléiade d'écrivains qui est en train de fonder le roman moderne en Espagne», pléyade en la que descuellan Galdós, Pardo Bazán, Valera y $\mathrm{Alas}^{8}$. Importa señalar que lo que se está negociando no es la fundación de la novela española moderna, sino la fundación de la novela moderna en España: sin duda, la incidencia en la Península de las letras europeas, y sobre todo francesas, era lo suficientemente importante como para alimentar la impresión de que aquel proceso podía formar un continuo transnacional. Pero nuestro crítico se esforzará por caracterizar la estética de la nueva novela artística o moderna, considerando la cuestión del realismo -en el sentido más amplio del término- no como un aspecto de la recepción de la novela francesa en España, sino como foco de un fenómeno literario autóctono. La propia figura de Pardo Bazán, en quien conviven la crítica literaria y la novelista, la lectora de novela francesa y la defensora de la tradición realista española, parece encarnar la dualidad inherente a aquel proceso cultural; para entonces ya había conquistado, a ojos de nuestro crítico, el rango de novelista: sin duda la publicación de La Tribuna, La dama joven y El cisne de Vilamorta y su creciente actividad periodística habían contribuido a aquel ascenso que la estaba conduciendo al nivel más alto de la sociedad literaria. Advierte Tannenberg que «les ouvrages de critique et d'histoire m'ont été très vantés, en particulier son étude sur le naturalisme (La Question palpitante); mais je n'en puis parler ne les connaissant pas»?.

Por lo que sé, la campaña publicitaria que acompañó a la edición de El cisne de Vilamorta comenzó con la inserción de un anticipo en El Globo el 18 de mayo de 1885 (Pardo Bazán 1885b). Las primeras reseñas que he podido localizar, aparecidas en La Época y La América, datan de mediados o finales de junio, de pocas semanas más tarde la de Orlando (pseudónimo de Antonio Lara y Pedraja) en la Revista de España, y de mediados de septiembre la de Clarín, también en El Globo, recogida en 1887 en Nueva campaña ${ }^{10}$. Con la excepción de Lara y Pedraja, que la juzga inferior a Un viaje de novios, la mayoría de sus críticos declaró que El cisne de Vilamorta constituía un progreso respecto de las anteriores novelas de la autora. Si no era raro que el mérito de las obras nuevas se calibrara

\footnotetext{
${ }^{8}$ Sorprende la ausencia de José María de Pereda, a quien Tannenberg conocería poco tiempo después en Santander. Quizá no estaba familiarizado todavía con su obra, pero sobre él versa el único libro sobre la novela española que llegó a publicar, en 1898 .

9 Con todo, en nota al pie cita las mismas obras a las que parecían aludir Tréverret y Savine, con la adición del Estudio crítico sobre Feijoo. La relación aparecía en las páginas iniciales de El cisne de Vilamorta.

10 Entre las reseñas más inmediatas cabe destacar, sin el menor afán de exhaustividad, las siguientes: Olavarría y Huarte (1885); Orlando (1885); Siles (1885); Vida (1885); Alas (1885), reimpreso en (2003: 781-785); Cabezas y León (1885).
} 
en función de la trayectoria de sus autores, la costumbre parece haber pesado más de lo habitual en la recepción de los primeros libros de Pardo Bazán, seguramente por recelo ante la determinación de aquella dama todavía joven que se aplicaba, con resultados notables, al cultivo de géneros y estudios tradicionalmente reservados a los hombres: para Clarín, El cisne de Vilamorta «refleja tal vez mejor que ninguna el carácter literario de quien escribió ese maravilloso libro de crítica que se llama La cuestión palpitante» (2003: 782), y acaso el recuerdo de aquel antecedente tan conocido viniera a apuntalar la legitimidad literaria de la autora.

En este sentido Tannenberg no se distingue de la tendencia general. A su entender, «il semble qu'à chaque production nouvelle le talent de la jeune romancière prenne plus d'assurance et d'ampleur», acendrando las cualidades que habían Ilamado la atención de la crítica y del público «lors de la publication de ses deux premiers romans»: «un tempérament énergique, une vue nette et précise des choses, un style coloré -le don de savoir observer et peindre». No queda claro si había leído aquellas novelas o si, como parece, se hacía eco de los tópicos fijados por la crítica del día desde la publicación de Un viaje de novios en 1881; en todo caso, veremos que en sus textos resuenan con frecuencia los juicios de Clarín, especialmente los contenidos su libro ...Sermón perdido, de 1885, que reseñaría en L'Espagne Politique et Financière en abril del año siguiente (1886b).

Tannenberg tiende a adoptar en sus causeries un enfoque comparativo, relacionando entre sí a los autores y las obras españoles de los que se ocupa y buscando correspondencias con la literatura francesa contemporánea. Por distintas fuentes sabemos que a mediados de la década de 1880 proyectaba escribir tres libros sobre la poesía, el teatro y la novela españolas del momento (Díaz Lage 2017): La poésie castillane contemporaine (Espagne et Amérique) salió en 1889, pero de sus estudios sobre el teatro sólo recogió en libro los referidos a Manuel Tamayo y Baus (en Tannenberg 1898a y 1903: 1-77), y sus artículos sobre la novela, salvo los dedicados a José María de Pereda (Tannenberg 1898b), quedaron olvidados en los periódicos donde aparecieron por primera vez. Las causeries de L'Espagne Politique et Financière son el testimonio más completo de sus ideas sobre la novela, y las referencias internas que contienen indican que proyectaba ofrecer un panorama cabal, si no completo y sistemático, de una época literaria.

Los primeros novelistas de quienes se ocupa, a propósito de sus publicaciones más recientes, son Galdós y Pardo Bazán. El artículo sobre El cisne de Vilamorta se comprende mejor si lo ponemos en relación con la reseña de Lo prohibido, novela que le parecía a Tannenberg una de las obras «plus curieuses que nous ait données jusqu'à ce jour le naturalisme espagnol» y que, según sus informes, no había encontrado «un accueil bien favorable» en Madrid (1886a). A juicio de nuestro crítico, aquella frialdad se debía a las inercias y las expectativas generadas por los Episodios nacionales y por las primeras Novelas españolas contemporáneas: la educación del público, escribe, «est encore à faire sur bien des points», y «un roman de pure analyse, sans aventure, sans intrigue, lui a sans doute paru un peu austère» (1886a). De acuerdo con lo establecido por Edmond de Goncourt en el prólogo a Chérie, de 1884, "le développement progressif du talent de $M$. Galdós révèle une tendance, de jour en jour plus accentuée, à diminuer dans le roman la 
part du romanesque, à réduire l'action aux proportions de la réalité» (1886a). Apenas un año separa aquel prólogo de la publicación de Lo prohibido, y ya las últimas novelas de Galdós, desde La desheredada, habían ido en aquella dirección: a pesar de la remisión, no parece que Galdós ocupe respecto de Goncourt una posición subalterna.

Si no me engaño, resuenan aquí los juicios de Alas sobre las constantes innovaciones narrativas de Galdós, no siempre bien aceptadas por la crítica ni por el público: parafraseando e incluso traduciendo algunos pasajes de la reseña de Tormento que Clarín publicó en El Día en julio de 1884 y recogió en ...Sermón perdido (Alas 2003: 511-523), Tannenberg compara con La Comédie Humaine y, sobre todo, con la saga de Les RougonMacquart el vasto mosaico que forman las novelas de Galdós posteriores a El doctor Centeno. Encuentra afinidades en la morfología de las series, pero no en otros aspectos:

L'entreprise de M. Galdós peut être comparée dans une certaine mesure à celle de I'auteur des Rougon Macquart, mais il ne faudrait pas trop forcer le rapprochement. Malgré l'identité de la conception générale, il y a entre les deux talents des divergences absolues; et s'il fallait chercher parmi les écrivains français quelque chose comme l'équivalent du romancier espagnol, ce serait encore M. Alphonse Daudet, peut-être aussi dans certaines parties humoristiques les de Goncourt, qui offriraient le meilleur terme de comparaison. (Tannenberg 1886a).

Como digo, el párrafo al que pertenecen estas palabras es una taracea de citas y paráfrasis de la reseña de Tormento por Clarín (cfr. especialmente Alas 2003: 514-515), aunque Tannenberg invierte el juego de correspondencias entre novelistas franceses y españoles que había planteado aquel en su recensión de La Tribuna. Daudet y los Goncourt no eran los referentes más recordados al tratar de Galdós, pero Clarín los había mencionado al analizar la técnica del diálogo y el «lirismo novelesco» de algunas obras contemporáneas: en su reseña de El idilio de un enfermo, aparecida en El Día el 20 de junio de 1884 y también recogida en ...Sermón perdido, advertía que en la novela «ha de dialogarse oportune», "como se puede observar que hacen Zola, Daudet, y hasta Galdós, en sus últimas novelas (no en otras que pecaban del defecto que censuro)» (Alas 2003: 603). Para el crítico asturiano, el lirismo y el humorismo son actitudes éticas que se transparentan en las técnicas dialogales y en la composición de la novela; el humorismo de Galdós, que a Tannenberg le recuerda a los hermanos Goncourt, lo relacionaba Clarín, en su reseña de El doctor Centeno, con los usos narrativos de Daudet, de Stendhal y de Balzac, tan dados como el novelista canario, según él, a intervenir en las descripciones y las narraciones: «el humorismo», escribe allí, "se luce en estas digresiones y entrometimientos, pero es a costa de lo principal en la novela; la exactitud de la imagen y el encanto de la mentación [sic]» (Alas 2004: 431). Se echa de ver que Tannenberg había asimilado los criterios estéticos de aquel a quien consideraba «le premier critique de l'Espagne» (Cuervo 1987: 207).

Me he detenido en este asunto porque una de las observaciones más interesantes de Tannenberg pasa por una comparación entre Galdós y Pardo Bazán: «dans son dernier livre, Le cygne de Vilamorta, elle témoigne, comme M. Galdós, une tendance de plus en plus accentuée vers l'art purement descriptif». Creo que el juicio debe interpretarse 
partiendo de esa comparación, sólo en apariencia incidental. Como hemos visto, a mediados de la década de 1880 ya era un tópico destacar la facilidad de la novelista coruñesa para las descripciones y la riqueza de sus pinturas de ambientes y caracteres: «es el talento de Emilia Pardo Bazán esencialmente descriptivo», comenta Jerónimo Vida (1885: 11) a propósito de El cisne de Vilamorta, y casi lo mismo repetirá Tannenberg en su reseña, citando a Clarín. Sin negar su importancia en la novela naturalista, algunos críticos juzgaron excesivas las descripciones, el colorido y la brillantez del estilo de la autora. Según Rafael Altamira -que glosa aquí una apreciación de Vida en su reseña de La Tribuna (Vida, 1884)- la «juventud literata, que es casi siempre juventud noveladora», corría el peligro de «dejarse entusiasmar por la luz del color, por las grandes manchas de colorido nuevecito, recién salido de la caja, brillando aún con sus reflejos metálicos o su pastosidad mineraloide» (Altamira 2016: 291). Si en otros lugares Altamira (2016 [1886]: 241, 288) había alabado la veracidad y la exactitud de las descripciones de la autora, tomando en cuenta Un viaje de novios y La Tribuna, la amonestación que acabo de citar va seguida de una alusión directa a ella.

Al relacionar la «tendance de plus en plus accentuée vers l'art purement descriptif» de El Cisne de Vilamorta con la evolución señalada por las últimas obras de Galdós, Tannenberg seguramente no se refería sólo al «predominio del color sobre el dibujo», que diría Altamira (ibid.), sino también a la condensación gradual de la trama y de la intriga para reducirlas, conteniendo la imaginación, a «las proporciones de la realidad y de la vida». Varios críticos contemporáneos señalaron que, en ese sentido, El cisne de Vilamorta desarrollaba los cambios ensayados en obras anteriores de la autora:

Será en vano que se le diga que en Un Viaje de novios había más originalidad, más gracia y frescura, una ligereza clásica encantadora; ella prefiere El cisne. Y tiene sus argumentos: El cisne es obra más pensada, más canónica se pudiera decir; su composición es mucho más sabia; la unidad de la acción más patente. (Alas 2003: 782).

Pero no todos los críticos coincidieron con las preferencias de Pardo Bazán ni con la opinión de Clarín, quien confesaba que «mientras leía las aventuras tristes y resobadas del pobre diablo que imitaba las rimas de Bécquer -Segundo García, El cisne- iba pensando en la habilidad recóndita con que el autor describe, analiza y llegado el caso inventa imitando el movimiento natural y probable de la vida, tal como se tiene que presentar en los lugares escogidos para el cuento» (Alas 2003: 782). El mismo Vida, que ya había notado algunos defectos en La Tribuna, confesaba su escepticismo hacia el despojamiento narrativo de $E$ I cisne de Vilamorta:

Antójaseme la acción, la trama, lo más endeble de toda la obra. Será muy natural, muy desembarazada de obstáculos y de episodios inútiles, todo lo que se quiera; ipero es tan sencilla, tan ingenua, tan primitiva, por decirlo así, que casi desde las primeras páginas se columbra todo lo que va a pasar! No hay allí artificio de ningún género, pero no hay tampoco gran interés. He oído decir a varias personas de refinado gusto literario y de vasto entendimiento, que les ha interesado vivamente la lectura de El cisne de Vilamorta: de mí no puedo afirmar otro tanto. Será prevención, será embotamiento 
de la sensibilidad; pero con franqueza declaro que no me ha llegado a lo vivo, como vulgarmente se dice. (Vida 1885: 11).

Todo indica que Tannenberg interpretó la obra -que debe haber leído con menos detenimiento que otras- como un avance en la trayectoria de Pardo Bazán y un jalón en la fundación de la novela española moderna. Si la riqueza y el relieve de verdad de las descripciones lo mueven a ser indulgente con "la simplicité un peu excessive de l'intrigue», es porque entiende que la autora, como otros novelistas, ha querido redefinir la especificidad estética del género, concentrándose en «estudiar y retratar en forma artística gentes y tierras que conozco, procurando huir del estrecho provincialismo, para que el libro sea algo más que pintura de usanzas regionales y aspire al honroso dictado de novela» (Pardo Bazán 1885c: III). En este sentido, El cisne de Vilamorta prolongaba el intento de La Tribuna, a pesar de que los dos amores de Segundo García, enlazados por su ambición de gloria y de ideal, no ofrecían la misma clase de interés que la trama de aquella, urdida con motivos que se ceñían a la lógica narrativa más corriente en su tiempo. En su análisis de la conjunción de aburrimiento y erotismo en algunas novelas de Galdós, Gonzalo Sobejano apuntaba que en El cisne de Vilamorta «el aburrimiento ostenta una presencia primordial»; y en efecto, Segundo se parece mucho al aburrido que, «incapaz de comprometerse en un proyecto trascendente, trata de escapar a su aburrimiento mediante la aventura», y «en la aventura -sea mortal, estética o amorosa- intenta recuperar lo perdido: el entusiasmo» (Sobejano 1969: 4). El arrebato pusilánime que lo caracteriza a lo largo de toda la novela es inseparable de esa tensión, en la que alienta también un profundo egoísmo, y la futilidad de su entusiasmo perdido es, en cierto modo, la pérdida del entusiasmo mismo.

Basándose en el prólogo de la novela, Tannenberg subraya que su asunto es «l'étude d'une maladie morale, la maladie du romantisme, dans l'âme d'un jeune homme de vingt ans». A diferencia de otros críticos, no se cuestiona las implicaciones de tal intento: al reseñarla en La Época, José de Siles sugirió, sin desarrollarla, la idea de que El cisne de Vilamorta pudiera ser un "Quijote del romanticismo» y, al mismo tiempo, lamentó «que en la obra de la señora Pardo Bazán ojos miopes hayan visto un proceso de la poesía» (Siles 1885: 6). Aunque su romántico se caracteriza por ser poeta en verso y no cultiva, que sepamos, ningún otro género, en el prólogo la novelista distinguía con claridad el Romanticismo como «época literaria» del «fenómeno aislado, como enfermedad, pasión o anhelo del espíritu» (Pardo Bazán 1885: Iv). La asimilación del Romanticismo residual con la poesía debía de ser tan característica de la conciencia subjetiva de la escritora identificada con el Naturalismo, como sintomática de las inercias estéticas que persistían en sectores no desdeñables del público lector (Valis 1986).

Tannenberg no entra a valorar, como podría haber esperado Pardo Bazán, si la obra tiene más de romántico o de naturalista; se limita a resumir la historia de su protagonista, reduciéndola al «semblant d'intrigue» de sus amores con Nieves, la esposa del diputado del distrito de Vilamorta. Llama la atención que ignore la figura de Leocadia Otero, la 
maestra, que para Clarín era «un personaje mucho más fuerte, representativo, original e interesante que la señora del diputado» (Alas 2003: 784) ${ }^{11}$. Es más:

Tal vez la novela hubiera sido más buena cambiando la perspectiva y presentando más cerca y más grande a la maestra, hablando más de ella, y menos de la señora frágil, que aunque está perfectamente tomada del pícaro mundo en que vive, ofrece menos novedad, y tonos mucho menos vivos. (ibid.).

Los amores posibles, y ya conquistados, parecen insignificantes comparados con las promesas de lo inalcanzable; pero los Cantos nostálgicos de Segundo, realización de sus aspiraciones poéticas, prenda y testimonio de su empeño por conquistar a Nieves, sólo llegan a imprimirse gracias al holocausto voluntario de Leocadia, sacrificio imprudente, por amor, de los bienes que su prudencia la había movido a reunir durante años. "No bodas, amor pedía él» (Pardo Bazán 1885c: 260).

Al final de la novela no queda claro qué rasgos de Segundo son consustanciales a sus veleidades románticas y cuáles son, sin más, los propios de un joven impulsivo y caprichoso. Puede que esta ambigüedad fuera un efecto buscado por la autora, pero al menos un crítico, el propio Vida, se planteó que la caracterización del personaje tenía poco que ver con el romanticismo: a su juicio, Segundo «apenas si tiene otra cosa de romántico que el pseudónimo y la melena, y acaso, acaso, la afición a hacer versos de cierta índole. En todo lo demás es un señorito de pueblo como otro cualquiera, que no hace ni dice nada que sobresalga del común de los mortales» (Vida 1885: 11). Tal vez recordando que la aspiración de la autora era «estudiar y retratar en forma artística gentes y tierras que conozco», Vida da por sentado que el cisne es trasunto de una o varias personas reales, y concede que quizá «el modelo que Emilia Pardo Bazán se propuso al trazar la figura de Segundo García» pudiera tener «aficiones y preferencias románticas» (Vida 1885: 11). No fue el único en tomar el prólogo al pie de la letra pues, como hemos visto, también Tannenberg dejó que los propósitos de la autora sesgaran su lectura de la novela.

En El cisne de Vilamorta reconoce Tannenberg "l'imitation évidente des procédés employés par le roman naturaliste français», no sólo en los asuntos y su encarnación en personajes y ambientes, sino sobre todo en los procedimientos técnicos: "on découvre à chaque page», escribe, que la autora "est en train d'apprendre le métier à l'école de Daudet et de Zola, qu'elle en a déjà acquis tous les trucs et en sait toutes les roueries». A diferencia de algunos críticos españoles de su tiempo (cfr. Díaz Lage 2009), Tannenberg no veía en el estilo de Pardo Bazán ni rastro de solecismo ni de galicismo, ni mimetismo torpe en la invención de sus asuntos y fábulas; las imitaciones que localizaba en sus obras se ceñían a las técnicas, sin duda cautivadoras, que habían imaginado los grandes escritores naturalistas y estaban reproduciendo ya otros de menor categoría: «cet apprentissage

\footnotetext{
$\overline{11}$ También para Eugenio de Olavarría y Huarte (1885: 15) Leocadia era «la verdadera protagonista» de la novela: «sin el tipo de la maestra, tan admirablemente dibujado, el libro sería un lago tranquilo cuya superficie es apenas rizada por ligeras piedrecillas; pero Leocadia le anima, le presta vida, le imprime carácter. Allí, en su corazón de madre, en su alma sedienta de los goces del amor está la lucha y ruge la tempestad desencadenada y sobreviene la catástrofe. Leocadia asume en sí todo el interés de la novela".
} 
n'aura pu être que fructueux pour elle, à condition qu'elle sache éviter le pastiche, les réminiscences (il y en a plus d'une dans Le Cygne de Vilamorta), et se créer à son tour une forme bien personnelle».

Por desgracia, Tannenberg no precisa cuáles son las reminiscencias que detecta en la novela, de modo que para aquilatar sus intuiciones habrá que proceder por conjeturas. Según Walter Pattison, en el propio designio de estudiar el romanticismo como pasión del espíritu y en el personaje de Leocadia se nota la huella de Madame Bovary (1971: 47), y Noël M. Valis, en su análisis del papel de la lectura en la parodia romántica de El cisne de Vilamorta (1986: 299-301), ha puesto de relieve la semejanza entre la escena de los fuegos artificiales y la de los comices agricoles que aparece en el capítulo vill de la segunda parte de aquella novela (1986: 307-308). Pero en los artículos de Tannenberg, el nombre de Gustave Flaubert brilla por su ausencia, mientras que los de Zola, Daudet y Goncourt salen al paso con frecuencia; y el joven crítico todavía no se permite juicios tan taxativos como el que emitirá en su semblanza de 1899, donde afirma, a propósito de La Tribuna, que la autora «débuta par le pastiche de Zola» (1899: 3; 1903: 305). La referencia a Daudet señala un influjo menos evidente que el del novelista de Médan, precedido por el escándalo, y el de los Goncourt, cuyos repujados verbales eran muy apreciados entonces. Ya hemos visto que Tannenberg disentía de Alas en cuanto a la afinidad de Pardo Bazán con los Goncourt que, a su juicio, eran «plutôt des peintres d'éventails et de paravents que des paysagistes émus et sincères»; y sin duda ella se congratularía de saber que, para un lector francés bien informado, «le pinceau de $M^{m e}$ Bazán est plus sobre et plus vrai, s'il est moins habile et moins brillant», que el de sus autores predilectos. Tannenberg desconfía sobre todo de los códigos y recursos ya tipificados de la escuela y los epígonos:

Les romanciers naturalistes, et surtout les plus infimes, ont une tendance à donner une importance exagérée à certains artifices de composition, à certains tours de style, et à réduire leur art à un procédé de fabrication: cette tendance est trop ridicule pour que des esprits supérieurs puissent y céder.

A mi juicio, una de las novelas francesas que resuenan en El cisne de Vilamorta es Numa Roumestan, de Daudet (1881), estudio de las vicisitudes de un temperamento meridional en las altas esferas de la política parisina, cuya influencia en la novela española de la década de 1880 merecería un análisis demorado. La obra circuló inmediatamente en versión original, y en 1882 se publicó en Madrid, por Alfredo de Carlos Hierro, una traducción al castellano (Pattison 1969: 57): ya en una reseña publicada en Los Lunes de El Imparcial el 19 de diciembre de 1881 (reproducida en La Publicidad y en La Diana, y recogida en Nueva campaña en 1887) observaba Clarín:

Yo conozco a muchos ex ministros españoles que, si leen Numa, tendrán que ponerse colorados; parece que es uno cualquiera de ellos; admitido el tipo como tal representación de toda una clase de hombres por un lado, y por otro de una raza, nada más artístico que los medios que Daudet discurre para poner de relieve el temperamento que examina. El estudio directo es en esta obra el meridional encumbrado, el hombre palabra, que no sabe más que mentir, que no tiene la palabra como un medio, sino como 
un fin supremo, que piensa algo para poder hablar, que no habla porque tenga algo que decir. Pero indirectamente resulta esta novela una sátira, muy discreta y de gran efecto, de las costumbres políticas. Poco insiste en esta relación el autor, y prefiere analizar la vida privada del hombre público; para ello deja casi siempre de tratar las escenas, indicadas por el asunto, del ministro enfrente del público, en la política, y nos cuenta sus relaciones con una cantante, sus falsedades, sus engaños en el hogar, sus promesas locas, contradictorias, nunca cumplidas, su prurito de mentir, y ofrecer, y olvidar. (Alas 2003: 894).

Al escribir El cisne de Vilamorta, Pardo Bazán debe de haber tenido presente también el tipo perediano de los hombres de pro, si no la trama de Pedro Sánchez, en que puede haber influido, a su vez, la obra de Daudet ${ }^{12}$. Pero el paralelismo entre aquella y Numa Roumestan es evidente: en ambas desempeña un papel importante la figura del provinciano que marcha a la capital con una posición modesta y, tras una ascensión poco clara, Ilega a diputado o a ministro, consiguiendo así una influencia que parece perdurar, tanto en la capital como en su región, más allá del ejercicio directo del cargo y del poder ${ }^{13}$. En sus visitas a su tierra natal o a su distrito, tanto Numa Roumestan como don Victoriano Andrés de la Comba son recibidos en olor de multitudes y agasajados por sus partidarios; pero don Victoriano no es, en sentido estricto, un hombre palabra, o al menos no en la misma medida que Numa: lejos de prodigar promesas y ofrecimientos, procura calmar los ánimos y contener las peticiones de sus paisanos, y sólo piensa en tentar al rival que podría derrotarlo en las próximas elecciones, ofreciéndole «un distrito en otra parte», para evitarse «el bofetón de una derrota por Vilamorta» (Pardo Bazán 1885c: 132). Son más bien sus paisanos quienes intentan forzar la voluntad del diputado y obtener de él promesas y compromisos, para cobrar los votos vendidos.

La descripción de la llegada de don Victoriano a Vilamorta recuerda a la escena inicial de la novela de Daudet, que transcurre en el circo de Aps-en-Provence. Mas frente al rozagante Numa Roumestan, que regresaba con aires triunfales a su país natal, don Victoriano es un prohombre cansado y consumido, que viene a tomar las aguas $y$ a descansar, como tantos otros enfermos, y abriga serias decepciones que los lectores conocerán en su conversación con Segundo, en el capítulo décimo; su semblante, "arado y marchito, mostraba impresas en signos visibles las zozobras de la lucha social, las vicisitudes de la banca política y los sedentarios trabajos del foro». Las alusiones a su carrera política se tiñen definitivamente de connotaciones agónicas, más allá de los usos fijados en el discurso social, cuando el narrador se refiere al exministro del distrito de Vilamorta como «el gladiador exánime», recordando quizá las arenas de Aps-en-Provence (Pardo Bazán 1885c: 51).

\footnotetext{
12 La afición de Pereda por Daudet, cuya obra conoció bien (Bonet 2006: 514, n.23.68), merecería un estudio más detenido: cfr. Gutiérrez Sebastián 2011, y las referencias bibliográficas que ella recoge. Ya Francisco Miquel y Badía señaló, en su reseña de Pedro Sánchez, que el personaje de don Augusto Valenzuela, "sin parecérselo en nada, recuerda sin embargo a Numa Roumestan, una de las figuras mejor trazadas por Alfonso Daudet» (apud González Herrán 1983: 215).

13 Sobre la representación y la dimensión de esta figura en la narrativa de José María de Pereda, véanse los estudios recogidos en González Herrán (2016), especialmente el que le da título al volumen, pp. 19-55.
} 
El modelo de Pardo Bazán debe haber sido el Numa Roumestan de la segunda mitad de la novela, que ya se ha tenido que enfrentar en varias ocasiones a las consecuencias de sus promesas irreflexivas (no sólo con la joven Alice Bachellery sino, sobre todo, con el tambourinaire Valmajour, cuyo referente real evocó Daudet en un capítulo de Trente ans de Paris que, según Clarín, se contaba entre sus mejores páginas ${ }^{14}$ ). La acción de El cisne de Vilamorta se circunscribe a esta «villita modesta, cabeza de partido» (Pardo Bazán 1885c: 10), en tanto que la de Numa Roumestan engrana el eje biográfico y político de París y Aps con un tercer vértice geográfico, la villa balneario de Arvillard-les-Bains. La clave termal, tan del gusto de nuestra autora, le da mayor espesor y amplitud al espacio de Vilamorta, contraponiendo a la capital convulsa y agónica las provincias nutricias y regeneradoras y asociando cada lugar con horizontes de posibilidades diferentes: el contraste entre quienes viven en Vilamorta y quienes están allí de paso conlleva una distorsión recíproca en la percepción de los espacios y lugares del otro, como se aprecia con frecuencia en las conversaciones de Segundo y de Nieves. Gracias a esa doble perspectiva, Pardo Bazán imbrica en una trama sencilla las descripciones de paisajes pintorescos, algunas escenas de la vida campestre y «la peinture finement observée des mœurs d'une petite ville de province en Espagne»: al reducir la extensión del lugar donde ambienta su obra, atraviesa el espacio de la ficción con trayectorias vividas que puedan adensarlo mediante el juego de presente y pasado, de recuerdos e ilusiones.

Este planteamiento permite estudiar los resortes del poder en una villa de provincias, en apariencia alejada de todo, y descubrir la concatenación de influencias que enlazaba, en intrincadas redes de dependencias, los poderes locales con el poder central; pero requiere personajes dinámicos que puedan encarnar aquella transición política y biográfica de lo local a lo central. En su balance del año literario de 1885 señalaba Ricardo Blanco Asenjo que en la novela española reciente las provincias habían ganado protagonismo en detrimento de la capital:

Hay un fenómeno en nuestra novela moderna que merece notarse; la mayoría de los autores se inclinan más a las apacibilidades del campo que a la lucha de la corte. ¿Será que los literatos que vienen de provincia guardan íntimo y poético recuerdo de aquellas localidades en que pasaron su infancia y su adolescencia y a donde se sienten de continuo atraídos por los lazos de la amistad y de la familia y por los recuerdos del pasado? Aparte de esto, Madrid, es una de las capitales que tienen costumbres menos caracterizadas y cuya sociedad es más descolorida y ofrece menos salientes a la observación y a la pintura, a lo cual se debe añadir que en España el escritor o hace la vida oscura del bohemio o la estudiosa y retirada del hombre grave, que se encuentra como en país extranjero más allá de las paredes de su gabinete o fuera del limitado círculo de sus amigos. (Blanco Asenjo 1885: 822).

\footnotetext{
14 De ese capítulo dice Clarín: «Mon tambourinaire es la historia verdadera de aquel pobre artista provenzal a quien Roumestan engaña engañándose a sí mismo, y que va a París a ganar en poco tiempo una celebridad y una fortuna que le han prometido y que no llegan nunca. Pues bien: el famoso episodio de la novela, que tiene mucha gracia, a pesar de cierta exageración y de unos amores románticos incidentales de poca verdad y menos oportunidad, queda muy por debajo, en mérito artístico, del capítulo en que Daudet nos pinta las aventuras cómico-elegíacas de su paisano el tamborilero, que va a deslumbrar y a aturdir a París batiendo el parche y tañendo un desventurado caramillo» (Alas 2003: 1244).
} 
Como es sabido, la idea de que Madrid no tenía costumbres venía de lejos; pero aquí la capital funciona como elemento de un centralismo cultural implícito, según el cual lo pintoresco estaba confinado en las regiones, en apariencia ajenas, de rechazo, al devenir del progreso, la política y la vida social. En El cisne de Vilamorta, Madrid tiene al menos dos caras: es el sueño de Segundo, que siente repugnancia por las miserias y las cominerías de su pueblo y ansía abrirse a horizontes más anchos en la corte; y es el origen de los males de don Victoriano, que vuelve a su tierra buscando las apacibilidades del campo para olvidar las luchas de la capital, y se ve enredado una vez más en las componendas que sostienen los cargos y las canonjías. Ya específicamente sobre esta novela, añade Blanco Asenjo:

Se supone que Vilamorta es un pueblo de Galicia, y con esto continúa la novela moderna su excursión por las comarcas occidentales de la península. Las ridículas aspiraciones de un poeta de provincia sirven de pretexto a la pintura de admirables cuadros de costumbres en que aparecen de mano maestra copiadas las artimañas del caciquismo de aldea y las pequeñeces de su política, las fiestas populares propias de la localidad y las ruines pasiones que habitando en el campo se envanecen al adoptar las exterioridades vanas de los que moran en ciudades de primer orden. (Blanco Asenjo 1885: 823).

En realidad, " las artimañas del caciquismo de aldea y las pequeñeces de su política» aparecen en la novela como origen y fundamento, o como condición previa, de la brillante carrera política de otro provinciano trasladado a Madrid. La elección de un espacio provincial daba pie a estudiar las costumbres y las «petites passions villageoises», arraigadas en los usos y las formas de sociabilidad del entorno más inmediato, pero encaminadas a trascender el ámbito regional e incidir en la política del centro. En las biografías de los personajes, entretejidas en la trama de la novela, se encarnan las dependencias políticas que, describiendo la estructura del Estado, trazan el mapa de la nación y cohesionan sus territorios (Labanyi 2000).

Como hemos visto, la reseña de Tannenberg no se circunscribe a los asuntos que Ilamaron la atención de la crítica española. Quizá porque escribía en un periódico francófono publicado en Madrid, se limita a resumir la intriga fundamental de la obra, ignorando elementos que debió de considerar incidentales; su análisis se centra en una que podía atraer la atención de su público, probablemente poco versado en literatura española: El cisne de Vilamorta era obra rica en reminiscencias de la novela francesa contemporánea, pero su acción se ambientaba en una pintoresca localidad provinciana española. Seguramente Tannenberg no la leyó con tanta atención como otras novelas estudiadas en sus causeries littéraires; pero valora con justeza su significado en la trayectoria ascendente de Pardo Bazán -una más, a su juicio, en «la pléiade d'écrivains qui est en train de fonder le roman moderne en Espagne»- y en la propia evolución del género.

\section{FINAL}


«La prosa ha triunfado en el año 1885, y de la prosa la novela es el género que ha obtenido victoria por toda la línea» (Blanco Asenjo 1885: 819): en efecto, sólo en aquel año se habían publicado Lo prohibido, el segundo tomo de La Regenta, Sotileza, El cisne de Vilamorta y José. Desde comienzos de la década, el auge de la novela había ido acompañado de una actividad crítica notable, que apuntalaba la autonomía del realismo español respecto de sus modelos franceses, incluso de los ligados al naturalismo, y respecto de la llamada novela de tendencia. Al Ilegar al final de este trabajo, tengo la impresión de que los juicios de Tréverret, Savine y Tannenberg ilustran, con las perspectivas propias de tres hispanistas de formación y situación diversas, un proceso interpretativo similar.

Cuando escriben sobre ella estos tres críticos, Pardo Bazán todavía no era, como luego será, por antonomasia, la autora de Los pazos de Ulloa. No ocupaba en el canon contemporáneo un lugar comparable al de Benito Pérez Galdós o José María de Pereda, y no gozaba del prestigio de Juan Valera ni de la notoriedad de Fernán Caballero, cuyas obras ya habían sido traducidas al francés décadas antes. En los estudios de Tréverret y de Savine resuena el éxito de La cuestión palpitante, que Tannenberg también conoce por referencias, pero admite no haber leído; parece confirmado, pues, que fue su faceta crítica la que antes llamó la atención de un sector del público francés, quizá intrigado por conocer las reacciones que había suscitado en España la novela francesa. Entre los artículos de Tréverret y los del joven crítico ruso, publicados en años consecutivos, parece haberse dado un cambio en la percepción de la actividad y la obra de Pardo Bazán: si para aquel la crítica literaria, la autora de La cuestión palpitante seguía primando sobre la narradora, para Tannenberg, seguidor también en esto del criterio de Clarín, en 1886 Pardo Bazán ya ocupaba un lugar central en el canon de los novelistas españoles contemporáneos. A juzgar por los comentarios de Savine, seguramente el punto de inflexión en su trayectoria fue la publicación de Bucólica en la Revista de España en 1884 y de El cisne de Vilamorta y La dama joven al año siguiente. Como ya hemos visto, el crítico languedociano fue sin duda quien más hizo por difundir en Francia la obra de la autora coruñesa, no sólo con estudios críticos, sino también con otras iniciativas más arriesgadas.

Tréverret, Savine y Tannenberg deben haber leído las obras de Emilia Pardo Bazán directamente en sus ediciones originales, que se conseguirían sin dificultad en las librerías de París y quizá también en las de Burdeos. Los tres parecen estar al tanto de las actualidades y las controversias de la cultura española, pero no siempre resulta clara la procedencia de las informaciones que manejan: pienso, por ejemplo, en los comentarios de Tréverret sobre Pascual López, novela muy poco conocida también en su tiempo, o en sus fugaces alusiones a la crítica española. Quizá basó las notas más generales de sus artículos en algún texto anterior -que hasta el momento no he logrado identificar- o en las palabras de algún conocido común, aunque todo indica que Pardo Bazán y él tuvieron contacto directo, ya por carta, ya en persona durante los viajes de ella. Como se ha señalado antes, cuando publicó Le Naturalisme en Espagne y la traducción de La cuestión palpitante Savine ya la conocía personalmente a través de Narcís Oller, y sus proyectos contaron con la aquiescencia o la cooperación de la autora. En cuanto a Tannenberg, lo más probable es que en 1886 sólo conociera a Pardo Bazán por sus obras y por las 
opiniones públicas y privadas de Clarín; si bien es cierto que pudieron coincidir en París por mediación de Emilio Castelar, seguramente entraron en trato directo al año siguiente, durante uno de los viajes de él por España.

Los artículos aquí estudiados ponen de manifiesto la importancia de los prólogos con que Pardo Bazán encabezó sus obras, no sólo en cuanto fuentes de información, sino también en cuanto instancias legítimas de enunciación autorial; sin duda estos autores veían en ellos una expresión fidedigna de la intención y la voluntad de la novelista, y posiblemente también una referencia para establecer con seguridad el sentido literal de sus textos. Los estudios de Tréverret y Tannenberg, a diferencia del de Savine, dialogan con los prólogos de La Tribuna y de El cisne de Vilamorta, en los que la autora había querido fijar su intento en una declaración concluyente de sus principios y sus intenciones. Sin perder de vista que son exposición de una doctrina literaria y esbozo de una historia de la novela en España, Tréverret también interpreta los textos de La cuestión palpitante como formulación de un programa estético que compromete la práctica de la novelista Emilia Pardo Bazán; de ahí que dedique buena parte de su estudio a cotejar lo expuesto en aquellas instancias intencionales con sus resultados en las obras de la autora, para valorar su coherencia moral y artística. Tannenberg acepta sin mayor cuestionamiento los propósitos de la autora como explicación del asunto y la intención de El cisne de Vilamorta, y parece basar en ellos su interpretación de la novela.

En un plano más general, quedan abiertos varios problemas para el futuro. De nuestros tres críticos, sólo Tréverret estaba vinculado a la Universidad francesa, por más que Tannenberg, licenciado en Letras por la Sorbona, abrigara durante años el proyecto de doctorarse en la misma institución con una tesis sobre Tirso de Molina. El examen de la prensa francesa ha permitido localizar un foco de recepción de la literatura española contemporánea, cuya actividad sólo en parte ha llegado a quedar registrada en libros. Los artículos de Tréverret sugieren que el interés por las cosas de la católica y monárquica España no fue ajeno a las controversias religiosas que acompañaron, en Francia, a los procesos de secularización y laicización del Estado y de la sociedad; es decir que, a pesar de la posición de su autor, se inscriben en un ámbito más amplio que el de los debates académicos. Los textos de Savine, sin duda los más conocidos, ponen de relieve la incidencia de la idea latina en algunas corrientes del hispanismo francés, cuyas conexiones con el felibre y con los círculos panrománicos europeos merecen más atención de la que aquí he podido dedicarles; también nos recuerdan que el cosmopolitismo centrípeto de los escritores españoles encontró asiento en la capital del siglo XIX gracias a elementos que, atraídos por países y literaturas periféricas, seguían más bien un impulso centrífugo. Los artículos de Tannenberg, por último, estaban Ilamados a formar parte de un panorama global de la literatura española contemporánea, que intentaba conciliar la lectura de la producción literaria del momento con el estudio directo, aunque parcial, de los avances de la crítica literaria española.

Los cauces de publicación de cada uno de nuestros críticos también brindan información relevante. Tréverret escribe en una revista que durante su dilatada trayectoria mantuvo una considerable influencia en la opinión católica, en tanto que Savine, colaborador habitual 
de Polybiblion, la Revue du Monde Latin y otras revistas literarias, se arriesga a publicar un volumen autónomo sobre el naturalismo español y promueve la traducción al francés de La cuestión palpitante, venciendo las dificultades que suelen acompañar a la edición de un libro. No conocemos la tirada de cada una de esas obras y, en principio, todo indica que pese a la intensa actividad del autor, traductor y editor, no recibieron demasiada atención por parte de la crítica literaria francesa: ¿creería Savine, en plena aproximación al naturalismo, que existía en Francia un público objetivo para ellas? ¿Vería un filón en la traducción de obras españolas, aprovechando aquel auge de la novela que describió Blanco Asenjo y el interés por las cosas de España que, según Tannenberg (1889: páginas iniciales, sin numeración), empezaba a cundir al Norte de los Pirineos?

La cuestión del público se nos plantea también al considerar la repercusión que pudieron alcanzar los artículos de Tannenberg en L'Espagne Politique et Financière, periódico efímero sobre cuya difusión y circulación tenemos muy pocos datos. En su diseño editorial conviven secciones dedicadas a la política y la economía de España con estudios de conjunto de la producción literaria reciente y reseñas de libros nuevos y con las inevitables Variétés y crónicas parisinas, en una combinación que parece dirigida a lectores franceses afincados en España o con intereses en ella, más que al público francés general. En la medida en que se refieren mayoritariamente a obras que no habían sido traducidas, los artículos literarios de Tannenberg parecen escritos para lectores franceses o francófonos capaces de leer en castellano, aunque nuestro crítico también tiende a traducir fragmentos escogidos de las obras reseñadas que, en ocasiones, se presentan como artículos independientes. Pero disponemos de tan poca información sobre la prensa francófona producida en España y sobre su proyección editorial que, por ahora, resulta difícil emitir hipótesis con seguridad. 


\section{APÉNDICE 1}

\section{Causerie littéraire.}

\section{Le Cygne de Vilamorta, roman de $\mathbf{M}^{\mathrm{me}}$. Emilia Pardo Bazán ${ }^{15}$}

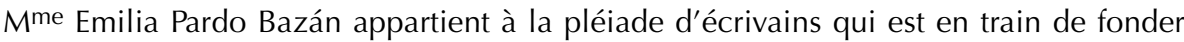
le roman moderne en Espagne. Elle en est encore presque à ses débuts et a déjà donné pourtant mieux que des promesses. Les ouvrages de critique et $\mathrm{d}^{\prime}$ histoire ${ }^{16} \mathrm{~m}^{\prime}$ ont été très vantés, en particulier son étude sur le naturalisme (La Question palpitante) ; mais je n'en puis parler ne les connaissant pas. J'ai été frappé, lors de la publication de ses deux premiers romans (Le Voyage de noces et La Femme tribun) des qualités remarquables qui s'y révélaient : un tempérament énergique, une vue nette et précise des choses, un style coloré -le don de savoir observer et peindre. Le Cygne de Vilamorta, qui a paru récemment, marque un progrès sur ses devanciers ; il semble qu'à chaque production nouvelle le talent de la jeune romancière prenne plus d'assurance et d'ampleur.

Le sujet du livre est l'étude d'une maladie morale, la maladie du romantisme, dans l'âme d'un jeune homme de vingt ans. "Le romantisme, nous dit l'auteur dans sa préface, a passé en tant qu'époque littéraire, et son influence a été presque nulle sur les mœurs ; mais comme phénomène isolé, comme maladie et passion de l'âme, il ne passera peut-être jamais ». Segundo García, petit poèterau de province, le cygne de Vilamorta, rêve de quitter sa ville natale pour aller chercher fortune et renommée à Madrid. II noue un semblant d'intrigue avec la femme de son député, lors d'une tournée de celui-ci dans le district. L'aventure, sur laquelle il fondait des espérances pour se fourrer dans le monde, finit par une catastrophe : le mari surprend un rendez-vous et meurt d'un coup de sang. Départ de la jeune femme pour Madrid, d'où elle ne donne plus signe de vie. Segundo essaye en vain de se rappeler à elle par la publication d'un volume de poésies, dont elle ne daigne pas accepter un exemplaire et qui, pour comble de déboires, est éreinté par toute la presse madrilène. II ne reste plus au jeune fou qu'à partir pour l'Amérique, où il apprendra peutêtre à mieux connaître la vie. Joignez à cette intrigue des paysages pittoresques, de jolies scènes de la vie champêtre, la peinture finement observée des mœurs d'une petite ville de province en Espagne, et vous aurez une idée assez nette de l'ensemble.

Ce qui m'a le plus frappé, à la lecture de ce volume, c'est l'imitation évidente des procédés employés par le roman naturaliste français. Je n'entends point par là que le talent de $M^{\text {me }}$ Pardo Bazán soit en passe de se franciser : bien espagnoles sont les mœurs qu'elle décrit, bien espagnole aussi et exempte de gallicismes la langue qu'elle parle. II n'en est pas moins vrai qu'on découvre à chaque page qu'elle est en train d'apprendre le métier à l'école de Daudet et de Zola, qu'elle en a déjà acquis tous les trucs et en sait toutes les roueries. Cet apprentissage n'aura pu être que fructueux pour elle, à condition qu'elle sache éviter le pastiche, les réminiscences (il y en a plus d'une dans Le Cygne de Vilamorta), et se créer à son tour une forme bien personnelle. Les romanciers naturalistes, et surtout

\footnotetext{
15 El cisne de Vilamorta, Madrid, Fernando Fe, 1885.

16 San Francisco de Asís, con prólogo de D. M. Menéndez Pelayo.- La Cuestión palpitante.- Los poetas épicos cristianos.- Sobre el Darwinismo.- Ensayo crítico de Feijoo. - Madrid, Fernando Fe.
} 
les plus infimes, ont une tendance à donner une importance exagérée à certains artifices de composition, à certains tours de style, et à réduire leur art à un procédé de fabrication : cette tendance est trop ridicule pour que des esprits supérieurs puissent y céder.

L'originalité du talent de $M^{\text {me }}$ Pardo Bazán est d'être essentiellement descriptif ; I'observation est de Leopoldo Alas, et elle est fort juste. L'éminent critique ajoute que sa manière rappelle celle des de Goncourt, mais le rapprochement me paraît un peu forcé. Les de Goncourt sont plutôt des peintres d'éventails et de paravents que des paysagistes émus et sincères ; le pinceau de $M^{\text {me }}$ Bazán est plus sobre et plus vrai, s'il est moins habile et moins brillant.

Boris de Tannenberg L'Espagne Politique et Financière II : 78 (10-vı-1886), p. 1

\section{APÉNDICE 2}

\section{Bibliographie}

El cisne de Vilamorta, par Emilia Pardo Bazán.- 1 vol. In-12, Madrid.

$M^{m e}$. Emilia Pardo Bazán, qui écrivait, il y a trois ans, un livre sur la querelle des réalistes et des idéalistes, a pris place par ses deux romans Le Voyage de Noces et la Femme tribun parmi les chefs de l'école nouvelle en Espagne. Dans son dernier livre, Le cygne de Vilamorta, elle témoigne, comme M. Galdós, une tendance de plus en plus accentuée vers l'art purement descriptif. Vilamorta est un village de Gallice où sont groupés les personnages et où se développe l'action du roman. Les aspects du pays, la vie champêtre, les petites passions villageoises, tout cela est peint avec un singulier relief de vérité, et nous rend indulgents pour la simplicité un peu excessive de l'intrigue.

L'Espagne Politique et Financière II : 78 (10-vı-1886), p. 3 


\section{REFERENCIAS BIBLIOGRÁFICAS}

Alas, Leopoldo, Ilamado Clarín (1885): "Un libro. El cisne de Vilamorta. Novela por doña Emilia Pardo Bazán", El Globo, XI: 3612 (17-IX-1885), p. 2.

(2003): Obras completas, IV: Crítica, ed. Laureano Bonet con la colaboración de Joan Estruch y Francisco Navarro, Oviedo, Ediciones Nobel.

Altamira, Rafael (2016 [1886]): El realismo y la literatura contemporánea, ed. Laureano Bonet, con la colaboración de Pau Miret, Sant Vicent del Raspeig, Publicacions Universitat d'Alacant.

Álvarez Junco, José (2001): Mater dolorosa: la idea de España en el siglo XIX, Madrid, Taurus.

Álvarez Rubio, María del Rosario (2007): Las historias de la literatura española en la Francia del siglo XIX, Zaragoza, Prensas Universitarias de Zaragoza.

Álvarez Rubio, María del Rosario (2012): "La literatura española en los estudios críticos de Antoine de Latour (1808-1881)", en Ángeles Ezama, Marta Marina, Antonio Martín, Rosa Pellicer, Jesús Rubio y Enrique Serrano (coords.): Aún aprendo. Estudios dedicados al profesor Leonardo Romero Tobar, Zaragoza, Prensas Universitarias de Zaragoza, pp. 395-403.

Blanco Asenjo, Ricardo (1885): “La literatura en 1885", La Ilustración Ibérica, III: 156 (26-XII), pp. 819, 822-823.

Bonet, Laureano (2002): "Clarín ante el canon: hacia una teoría del "oportunismo» literario", en Luis Federico Díaz Larios, Jordi Gracia, José María Martínez Cachero, Enrique Rubio Cremades, Virginia Trueba Mira (eds.): La elaboración del canon en la literatura española del siglo XIX (Barcelona, 20-22 de octubre de 1999), Barcelona, Promociones y Publicaciones Universitarias, pp. 81-95.

Bonet, Laureano, ed. (2006): José María de Pereda, Peñas arriba, Barcelona, Galaxia Guntenberg- Círculo de Lectores.

Botrel, Jean-François (1982): "La iglesia católica y los medios de comunicación impresos en España de 1847 a 1917: doctrina y prácticas", en VV. AA., Metodología de la historia de la prensa española, Madrid, Siglo XXI, pp. 119-176.

Botrel, Jean-François (2008): "Petits échos du Grand Réalisme espagnol dans la critique littéraire française", en Alain Deguernel y Christine Rivalan Guégo (dirs.): Les Espagnes, número monográfico de Atala. Revue du Cercle de Réflexion Universitaire du Lycée Chateaubriand, 11, pp. 271-286.

Boutry, Vincent (2011): "La presse religieuse", en Dominique Kalifa, Philippe Régnier, Marie-Ève Thérenty y Alain Vaillant (dirs.), pp. 437-444.

Cabezas y León, Salvador (1885): "El cisne de Vilamorta", La Unión, IV: 1131 (6-X1885), p. 2. 
Cabo Aseguinolaza, Fernando (2012): Historia de la literatura española, dirigida por José-Carlos Mainer, 9. El lugar de la literatura española, Barcelona, Crítica.

Cazottes, Gisèle (1982): La presse périodique madrilène entre 1871 et 1885, Montpellier, Université Paul Valéry.

Charques Gámez, Rocío (2016): "Emilia Pardo Bazán en la prensa francesa. Revue politique et littéraire. Revue Bleue", La Tribuna: cadernos de estudos da Casa-Museo Emilia Pardo Bazán, 11, pp. 73-85.

Clemessy, Nelly (1973): Emilia Pardo Bazán, romancière (la critique, la théorie, la pratique), Paris, Centre de Recherches Hispaniques.

Cuervo, Rufino José (1987): Epistolario de -bcon Alfred Morel-Fatio, Gaston Paris y otros hispanistas de lengua francesa, ed. Mario Germán Romero, Bogotá, Instituto Caro y Cuervo.

Daudet, Alphonse (1881): Numa Roumestan, Paris, G. Charpentier, Éditeur.

Díaz Lage, Santiago (2006): “Dos versiones de 'La cigarrera', texto olvidado de Emilia Pardo Bazán", La Tribuna: Cadernos de Estudos da Casa-Museo Emilia Pardo Bazán, 4, pp. 355-384.

Díaz Lage, Santiago (2009): "La «infatigable coleccionista de vocablos»", en José Manuel González Herrán, Cristina Patiño Eirín y Ermitas Penas Varela (eds.): La literatura de Emilia Pardo Bazán, A Coruña, Casa Museo Emilia Pardo Bazán-Fundación Caixa Galicia, pp. 255-264.

Díaz Lage, Santiago (2013): "Sobre los conceptos de estilo y plan en la estética de la novela española durante la segunda mitad del siglo XIX", en António Apolinário Lourenço, Maria Helena Santana y Maria João Simões (eds.): O século do romance: Realismo e Naturalismo na ficção oitocentista, Coimbra, Centro de Literatura Portuguesa da Universidade de Coimbra, pp. 179-190.

Díaz Lage, Santiago (2017): "Boris de Tannenberg y la literatura española hacia 1885-86", en Ana María Freire López y Ana Isabel Ballesteros Dorado (coords.), pp. 133-155.

Freire López, Ana María (2001): "La primera redacción, autógrafa e inédita, de los Apuntes Autobiográficos de Emilia Pardo Bazán", Cuadernos para Investigación de la Literatura Hispánica, 26, pp. 305-336.

Freire López, Ana María (2005): "Las traducciones de la obra de Emilia Pardo Bazán en vida de la escritora", La Tribuna: Cadernos de Estudos da Casa-Museo Emilia Pardo Bazán, 3, pp. 21-38.

Freire López, Ana María y Ana Isabel Ballesteros Dorado (coords.) (2017): La literatura española en Europa, 1850-1914, Madrid, Editorial UNED.

Fuentes, Víctor (1971): "La aparición del proletariado en la novelística. Sobre La Tribuna", Grial: revista galega de cultura, 31, pp. 90-94. 
García Castañeda, Salvador (2017): "Pereda traducido: la traducción francesa de Sotileza", en Ana María Freire López y Ana Isabel Ballesteros Dorado (coords.), pp. 133-155.

González Arias, Francisca (1989): "Emilia Pardo Bazán y los hermanos Goncourt: afinidades y resonancias", Bulletin Hispanique, XCI: 2, pp. 409-446.

González Herrán, José Manuel (1983): La obra de Pereda ante la crítica literaria de su tiempo, Santander, Delegación de Cultura del Excmo. Ayuntamiento de SantanderEdiciones de Librería Estvdio.

González Herrán, José Manuel (1988): "La Tribuna, de Emilia Pardo Bazán, entre romanticismo y naturalismo", en Yvan Lissorgues (ed.): Realismo y naturalismo en España en la segunda mitad del siglo XIX, Barcelona, Anthropos, pp. 497-512.

González Herrán, José Manuel (1989): "Estudio introductorio" a Pardo Bazán (1989 [1891]), pp. 7-103.

González Herrán, José Manuel (2011): "La cigarrera y el militar: Carmen (1845) de Prosper Merimée, La Tribuna (1883) de Emilia Pardo Bazán, y algunos textos más", en Enrique Rubio, Marisa Sotelo, Marta Cristina, Virginia Trueba y Blanca Ripoll (eds.), pp. 193-206.

González Herrán, José Manuel (2016): "Érase un muchacho...», y otros estudios peredianos (1976-2016), Santander, Sociedad Menéndez Pelayo.

González Raposo, Benito (1999): O protestantismo en Galicia: unha historia centenaria, esquecida, Vigo, Edicións Xerais de Galicia.

Gutiérrez Díaz-Bernardo, Esteban (2009), "Introducción" a Albert Savine (2009 [1886]), pp. 13-120.

Gutiérrez Sebastián, Raquel (2011): "Ecos de Daudet en Pereda", en Enrique Rubio, Marisa Sotelo, Marta Cristina, Virginia Trueba y Blanca Ripoll (eds.), pp. 225-234.

Hemingway, Maurice (1983): Emilia Pardo Bazán: the Making of a Novelist, Cambridge-London-New York- New Rochelle- Melbourne-Sydney, Cambridge University Press.

Hibbs-Lissorgues, Solange (1995): Iglesia, prensa y sociedad en España (1868-1904), Alacant, Institut de Cultura "Juan Gil Albert".

Kalifa, Dominique, Philippe Régnier, Marie-Ève Thérenty y Alain Vaillant (dirs.) (2011): La civilisation du journal: histoire culturelle et littéraire de la presse française au XIX $X^{\mathrm{C}}$ siècle, Paris, Nouveau Monde Éditions.

Labanyi, Jo (2000): Gender and Modernization in the Spanish Realist Novel, Oxford, Oxford University Press.

Leroy-Brunneau, Christiane (1978): Albert Savine et l'Espagne. Thèse pour le Doctorat d'Université, Université de Paris-Sorbonne, Paris IV.

"Libros nuevos", La Época, XXXVIII: 12239 (18-VIII-1886), p. 4. 
López Jiménez, Luis (1990): “A. Germond de Lavigne, primer traductor al francés de Benito Pérez Galdós", El Guiniguada, 1, pp. 285-293.

Olavarría y Huarte, Eugenio de (1885): "Revista de Madrid", La América, XXVI: 11 (13-VI-1885), pp. 15-16.

Orlando [Antonio Lara y Pedraja] (1885): "Revista literaria. El cisne de Vilamorta", Revista de España, CIV: 416, pp. 626-627.

Pardo Bazán, Emilia (1885a): "Les réalistes. Stendhal, Balzac, Flaubert, par Madame -(traduit de I'espagnol, par M. Albert Savine, correspondant de l'Académie royale des Bonnes-Lettres de Barcelone)", La Revue du Monde Latin, V: 1 (enero), pp. 90-104.

Pardo Bazán, Emilia (1885b): "El cisne de Vilamorta", El Globo, XI: 3490 (18-V1885), pp. 1-2.

Pardo Bazán, Emilia (1885c): El cisne de Vilamorta, Madrid, Librería de Fernando Fe.

Pardo Bazán, Emilia (1886): Le Naturalisme, trad. Albert Savine, Paris, Nouvelle Librairie Parisienne Giraud et Cie., Éditeurs.

Pardo Bazán, Emilia (s. d. [1899]): La España de ayer y la de hoy (Conferencia de París), Madrid, s.n.

Pardo Bazán, Emilia (1989 [1891]): La cuestión palpitante, ed. José Manuel González Herrán, Barcelona- Santiago de Compostela, Anthropos- Servizo de Publicacións e de Intercambio Científico da Universidade.

Pardo Bazán, Emilia (1999 [1881]): Un viaje de novios, en Obras completas i (Novelas), ed. José Manuel González Herrán y Darío Villanueva, Madrid, Fundación José Antonio de Castro, pp. 195-404.

Pardo Bazán, Emilia (1999 [1883]): La Tribuna, ed. Benito Varela Jácome, Madrid, Cátedra.

Pattison, Walter T. (1969): El Naturalismo español: historia externa de un movimiento literario, Madrid, Gredos.

Pattison, Walter T. (1971): Emilia Pardo Bazán, New York, Twayne Publishers, Inc.

Robert, Vincent (2011): "Paysages politiques, cohérences médiatiques", en Dominique Kalifa, Philippe Régnier, Marie-Ėve Thérenty y Alain Vaillant (dirs.), pp. 213-248.

Romero Tobar, Leonardo (1992): "Introducción" a su ed. de Juan Valera, Pepita Jiménez, Madrid, Cátedra (4 ${ }^{\mathrm{a}}$ ed.).

Rubio, Enrique, Marisa Sotelo, Marta Cristina, Virginia Trueba y Blanca Ripoll (eds.) (2011): La literatura española del siglo XIX y las literaturas europeas (Barcelona, 22-24 de octubre de 2008), Barcelona, Universitat de Barcelona- PPU.

Savine, Albert (2009 [1885]): Le naturalisme en Espagne. Simples notes/ El naturalismo en España. Simples notas, ed. Esteban Gutiérrez Díaz-Bernardo, Vigo, Editorial Academia del Hispanismo.

Siles, José de (1885): "Dos libros nuevos", La Época, XXXVII: 11828 (21-VI-1885), p. 6 . 
Sobejano, Gonzalo (1969): "Aburrimiento y erotismo en algunas novelas de Galdós", Anales Galdosianos, 4, pp. 3-11, p. 4.

Sotelo Vázquez, Marisa (2002): "Introducción" a su ed. de La Tribuna, Madrid: Alianza Editorial, pp. 7-33.

Tannenberg, Boris de (1886a): "Causerie littéraire. Le dernier roman de Pérez Galdós", L'Espagne Politique et financière, II: 66 (11-IV-1886), p. 1.

Tannenberg, Boris de (1886b): "Causerie littéraire. Monsieur Leopoldo Alas", L'Espagne Politique et financière, II: 68 (18-IV-1886), p. 1.

Tannenberg, Boris de (1886c): "Causerie littéraire. Le Cygne de Vilamorta, roman de Mme. Emilia Pardo Bazán”, L'Espagne Politique et Financière, II: 78 (10-VI-1886), p. 1.

Tannenberg, Boris de (1889): La poésie castillane contemporaine (Espagne et Amérique), par-, Paris, Librairie Académique Didier- Perrin et Cie., Libraires-Éditeurs.

Tannenberg, Boris de (1899): "Variétés. Doña Emilia Pardo Bazán", Le Journal des Débats Politiques et Littéraires, CXI: 100 (11-IV-1899), p. 3.

Tannenberg, Boris de (1903): L'Espagne littéraire: portraits d'hier et d'aujourd'hui. Première Série. Manuel Tamayo y Baus. Marcelino Menéndez y Pelayo. José María de Pereda. Doña Emilia Pardo Bazán, Paris-Toulouse, Alphonse Picard et Fils, Libraireséditeurs- Édouard Privat, Libraire-éditeur.

Thion Soriano-Mollá, Dolores (2003): Pardo Bazán y Lázaro: del lance de amor a la aventura cultural (1888-1919), Madrid, Fundación Lázaro Galdiano- Ollero y Ramos.

Tréverret, Armand-Germain de (1885a): "La littérature espagnole contemporaine: le roman et le Réalisme", Le Correspondant: recueil périodique. Religion, Philosophie, Politique, Sciences, Littérature, Beaux-Arts, CXXXVIII: 6 (25-III-1885), pp. 1096-1116; CXXXIX: 1 (10-IV-1885), pp. 150-167; y CXXXIX: 2 (25-IV-1885), pp. 324-342. Puede consultarse en http://gallica.bnf.fr [último acceso: 20-09-2017].

Tréverret, Armand-Germain de (1885b): "La littérature espagnole contemporaine. Un poète philosophe", Le Correspondant: recueil périodique. Religion, Philosophie, Politique, Sciences, Littérature, Beaux-Arts, CXL: 4 (25-VIII-1885), pp. 686-708.

Tréverret, Armand-Germain de (1887): "Emilio Castelar", Le Correspondant CXLVIII: 4 (25-VIII-1887), pp. 615-630; CXLVIII: 5 (10-IX-1887), pp. 812-829; y CXLVIII: 6 (25IX-1887), pp. 993-1005.

Valis, Noël M. (1986): "Pardo Bazán's El cisne de Vilamorta and the Romantic Reader", Modern Language Notes, Cl: 2 (marzo 1986), pp. 298-324.

Vida, Jerónimo (1884): "Bibliografía. La Tribuna, novela de Emilia Pardo Bazán", Boletín de la Institución Libre de Enseñanza, 170, pp. 76-77.

Vida, Jerónimo (1885): "El cisne de Vilamorta", La América, XXVI: 12 (28-VI-1885), pp. 11-12. 